University of Louisville

ThinkIR: The University of Louisville's Institutional Repository

College of Arts \& Sciences Senior Honors

Theses

College of Arts \& Sciences

$5-2014$

\title{
The human immune response to the flagellins of Burkholderia dolosa.
}

Molly McDonald

University of Louisville

Follow this and additional works at: https://ir.library.louisville.edu/honors

Part of the Biology Commons

\section{Recommended Citation}

McDonald, Molly, "The human immune response to the flagellins of Burkholderia dolosa." (2014). College of Arts \& Sciences Senior Honors Theses. Paper 82.

http://doi.org/10.18297/honors/82

This Senior Honors Thesis is brought to you for free and open access by the College of Arts \& Sciences at ThinkIR: The University of Louisville's Institutional Repository. It has been accepted for inclusion in College of Arts \& Sciences Senior Honors Theses by an authorized administrator of ThinkIR: The University of Louisville's Institutional Repository. This title appears here courtesy of the author, who has retained all other copyrights. For more information, please contact thinkir@louisville.edu. 


\title{
The Human Immune Response to the Flagellins of

\author{
Burkholderia dolosa
}

\author{
By \\ Molly McDonald
}

Submitted in partial fulfillment of the requirements for Graduation summa cum laude

and

for Graduation with Honors from the Department of Biology

University of Louisville

May 2014 


\section{Table of Contents}

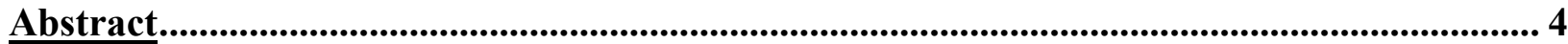

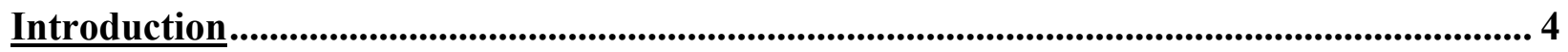

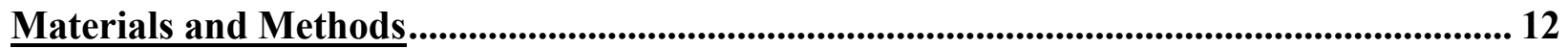

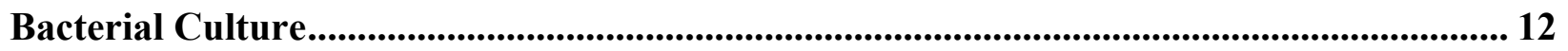

Quantitative Analysis of Bacterial Motility .................................................................................. 13

Qualitative Analysis of Bacterial Motility during Infection .............................................. 14

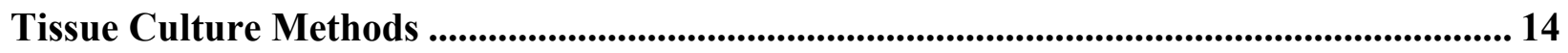

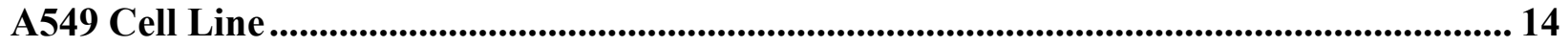

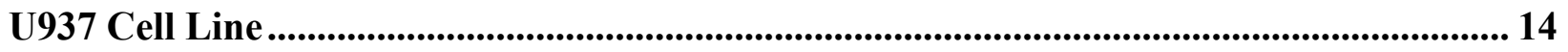

PMA Optimization in U937 Cells ................................................................................................ 15

PMA-Induced Differentiation of U937 Cells ...................................................................... 16

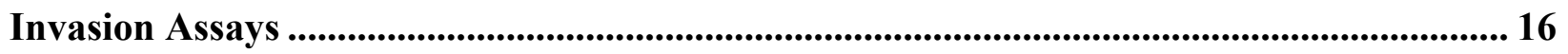

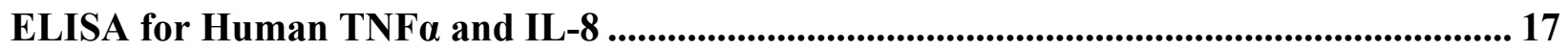

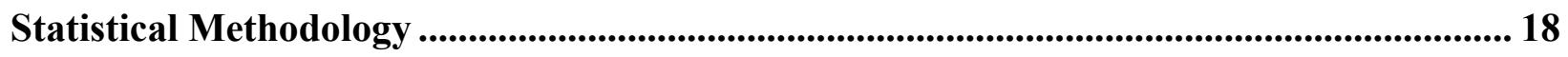

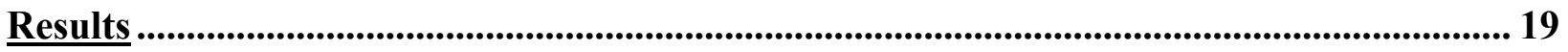

Verification of motility of $B$. dolosa flagellar mutants................................................................. 19

The motility of bacterial strains in tissue culture medium ............................................. 20

TNF $\alpha$ production in A549 cells in response to B. dolosa strains ......................................... 21

IL-8 production in undifferentiated $\mathrm{U} 937$ cells in response to $B$. dolosa strains ................... 23

Time-dependent IL-8 production in U937 undifferentiated cells in response to $B$. dolosa

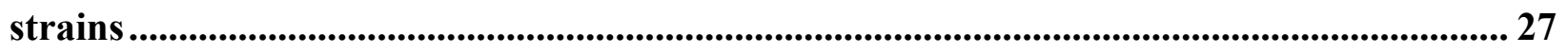

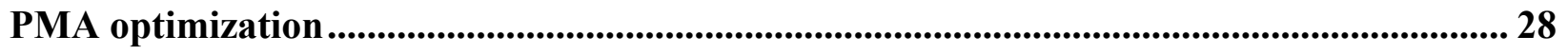


IL-8 production in differentiated cells in response to $B$. dolosa strains

Copmaring IL-8 secretion from undifferentiated to differentiated U937 cells in response to

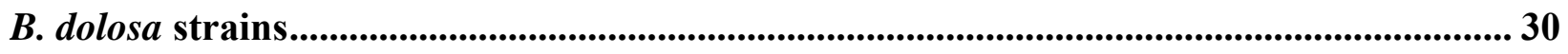

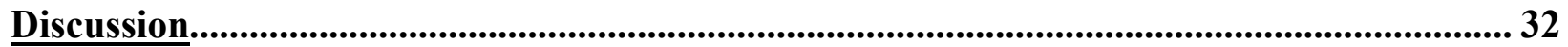

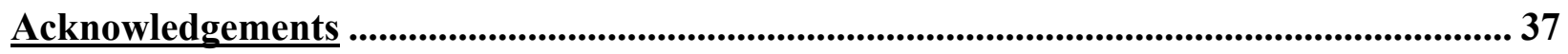

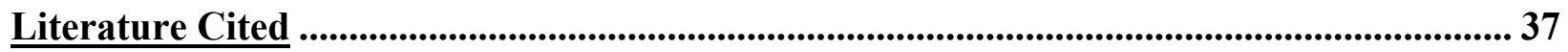

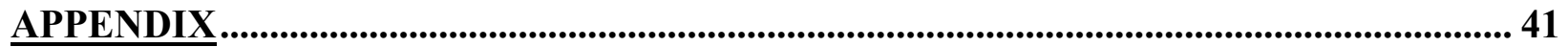

I. Supplemental Tables ............................................................................................................................ 42

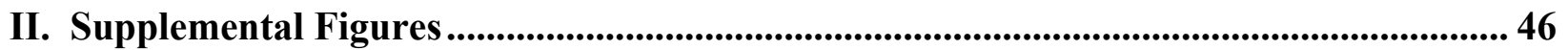




\section{Abstract}

Cystic Fibrosis (CF) is the most commonly inherited lethal disorder in Caucasian populations. Chronic bacterial infection both decreases lung function and lowers the quality of the CF patient's life. In one of the most recent CF epidemics, Burkholderia dolosa, an organism previously uncharacterized as an epidemic strain, infected over forty patients and led to the death of over seven patients at Children's Hospital Boston. Preliminary research revealed that this strain of B. dolosa possesses genes for two distinct types of flagella, which is uncommon in bacterial pathogens. In this study we examine the interaction of human cells and B. dolosa, focusing on the human inflammatory response to these two types of B. dolosa flagella. The findings of this study could provide insight into B. dolosa pathogenesis, so that effective therapeutics may be designed to combat this organism in the future.

\section{Introduction}

Cystic Fibrosis (CF) has a prevalence of 1/2500 live Caucasian births, making it the most commonly inherited lethal disorder in the Caucasian population [1]. The mutation of the chloride ion transporter gene, CFTR, that results in CF leads to the production of a thick, sticky mucous in the lungs and gastrointestinal tract of CF patients, creating a prime breeding ground for bacteria $[2,3]$. The major pathogens infecting the lungs of CF patients are Pseudomonas aeruginosa, Staphylococcus aureus, Haemophilus influenza, Stenotrophomonas maltophilia, and members of the Gram-negative Burkholderia cepacia complex (Bcc) [1], which is comprised of over seventeen closely related species including the intracellular opportunist B. dolosa [4]. P. aeruginosa is the most prevalent CF opportunist, found in approximately $80 \%$ of CF lungs [5]. 
Infections with these common pathogens are often the ultimate cause of mortality in $\mathrm{CF}$, limiting the lifespan and quality of life for CF patients significantly [1].

All members of the Bcc have been isolated from the lungs of CF patients. However, the more prevalent $\mathrm{Bcc}$ members isolated from $\mathrm{CF}$ patients are B. multivorans, B. cenocepacia, $B$. ambifaria and B. dolosa. Although members of the Bcc are the rarest among the common CF pathogens, its members are extremely resilient in their ability to survive in numerous niches ranging from soils, plastics and cosmetics, to supposedly sterile solutions such as mouthwashes and disinfectants [4]. While P. aeruginosa and other opportunistic pathogens are commonly found as commensal organisms in humans, B. dolosa is not [6]. This implies that infection by members of the Bcc is either acquired nosocomially or from the environment.

Members of the Bcc are capable of producing a necrotizing pneumonia in infected patients, characterized by a rapid decline in lung function (1-3 months) and a definite mortality after the bacteria enter the bloodstream during sepsis. This is often called the "cepacia syndrome" in CF clinics [7]. Certain species within the Bcc are capable of facile patient-topatient transmission and have caused epidemics in many CF clinics worldwide. The most common epidemic species of the Bcc are B. cenocepacia and B. dolosa [8]. The capacity of these organisms for epidemic has resulted in the enforcement of strict regulations for those patients colonized with members of the Bcc, in which patients are isolated from the general $\mathrm{CF}$ population. This leads to a greater reduction in the quality of life for those CF patients infected with members of the Bcc.

Prior to 1998 , B. dolosa had not been implicated as an epidemic-causing strain. Like other members of the Bcc it is assumed that B. dolosa is capable of living in soils, rendering this species an even greater threat. Soil organisms have evolved defense mechanisms to prevent 
predation and competition within the surrounding area out of necessity. In a study from George Church's group, species within samples of soil bacteria were isolated due to their capacity to grow on antibiotics as the sole carbon source [9]. These species were determined to be very phylogenetically diverse and many were closely related to human pathogens. This study showed that the Burkholderiales constituted $41 \%$ of the isolated species, followed by lesser percentages of the Pseudomonadales, Enterobacteriales, Actinomycetales, Rhizobiales and Sphingobacteriales. This suggests that many of those bacterial species commonly invading CF patients may be able to not only tolerate antibiotics but to actually use them as a food source, with the Burkholderiales as the most diverse and abundant threat of the group.

Genomic research on the Bcc has revealed that these bacteria have large genomes, consisting of multiple large replicons. B. dolosa has a $6.42 \mathrm{Mb}$ genome with no plasmids, consisting of $66.81 \%$ GC pairs, similar to the GC content of Pseudomonas species [10]. The genome of B. cenocepacia J2315, formerly the most prevalent Bcc member isolated from $\mathrm{CF}$ patients, has been fully characterized and was surprisingly found to contain three chromosomal replicons and one plasmid. All sequenced Bcc members have likewise been found to contain three replicons and zero to five plasmids [11]. Virulence traits attributed to B. dolosa and certain other members of the Bcc include intrinsic antimicrobial resistance, biofilm formation, catalase and superoxide dismutase (SOD) for disabling lysosomal digestion within mammalian host cells, invasion capability and intracellular survival within host cells for up to five days, lipopolysaccharide (LPS) that is four to five times more endotoxic than LPS of P. aeruginosa, quorum sensing abilities, siderophore production for iron sequestration, three Type III Secretion Systems, and flagella for motility [reviewed in 4]. Based on this data in conjunction with the observed pathogenicity of B. dolosa AU0158 in CF patients, it is crucial that the mechanism by 
which these species interact with their hosts be understood; this will pave the way to the discovery of effective therapeutics that can be used to combat them. A common pathogenic mechanism that has been thoroughly studied in model pathogens such as $P$. aeruginosa and Escherichia coli involves the specific interaction between bacterial flagella and the host's immune cells.

Approximately half of bacilli and virtually all spiral and curved bacteria express flagella for motility [12]. The majority of motile bacteria express a single, polar flagellum composed of flagellin subunits. The AU0158 clinical isolate of B. dolosa, which caused the most recent outbreak in a CF clinic at Children's Hospital Boston, was found to contain genes encoding both a single, polar flagella as well as multiple, lateral flagella in a previous unpublished study by Dr. Yoder-Himes (Supplemental Figure 1). Polar flagella are utilized during swimming in liquids and are the most common flagellar type amongst pathogenic bacteria, while lateral flagella assist in swarming over surfaces and are generally absent in pathogenic bacteria. Generally, a microbe contains genes for expressing only one type of flagellum that is sufficient for motility in its native environment [13]. However, lateral flagellar genes have been found in B. pseudomallei and B. mallei, both human biosafety level 3 (BSL 3) pathogens, where the lateral flagella are essential for intracellular movement [14].

Besides B. dolosa, the few other pathogens containing genes for both types of flagella, such as Vibrio parahaemolyticus, often express the polar flagellum alone while grown in liquid culture, but express both polar and lateral flagella when grown on solid media. In a 2003 study, the polar flagellum of $V$. parahaemolyticus was shown to act as a sensor that regulated the expression of the lateral flagellar genes [13]. Decreased flagellar rotation speed when introduced into a more viscous solution resulted in increased expression of lateral flagella in this species. 
Expressing two flagella has high energetic cost, but based on this research, one can see the benefit of possessing both types of flagella in an environment such as viscous CF sputum.

To determine if and when both flagellar types are expressed in B. dolosa, Dr. YoderHimes conducted quantitative real time polymerase chain reaction (qRT-PCR) experiments for quantitation of fliC and lafA transcripts. It was found that fliC transcripts were overexpressed in comparison to lafA transcripts under several environmental conditions, although both flagella do appear to be expressed rather constitutively (Supplemental Figure 2). In this same study, A549 human alveolar basal epithelial cells were infected with B. dolosa AU0158 and the abundance of gene transcripts encoding both $B$. dolosa flagellar types was compared from intracellular bacteria. The lafA gene (encoding the lateral flagellin monomer) was expressed along with fliC (encoding the polar flagellin monomer) during initial invasion; once the bacteria successfully entered the A549 cells at two hours post-infection (hpi), lafA expression diminished before gradually increasing to initial expression levels at $48 \mathrm{hpi}$.

Mammals have evolved a response to the flagellin subunits of bacterial polar flagella, mediated by Toll-like receptor 5 (TLR5) of the innate immune response [15]; whether the same interaction is true between lateral flagella and TLR5 is unknown, because little research has been conducted on lateral flagella in pathogenesis. TLRs are a group of evolutionarily conserved receptor proteins that recognize pathogen-associated molecular patterns (PAMPs) such as flagella, LPS of Gram-negative species, and peptidoglycan of Gram-positive species [16]. Binding of TLR5 to bacterial flagellin results in the activation of the MyD88-dependent signaling pathway, inducing the maturation of antigen-presenting cells such as macrophages and dendritic cells, as well as the secretion of pro-inflammatory molecules from these cells [15]. During this cascade event the enzyme NF-kB (nuclear factor kappa-light-chain-enhancer of 
activated B cells) is translocated to the nucleus of the mammalian cell where it activates NF- $\mathrm{kB}$ dependent genes such as those encoding chemokines and pro-inflammatory cytokines. These molecules trigger the innate and adaptive immune responses through chemotactic recruitment of additional cells involved in immunity. Because of this mammalian defense mechanism, bacterial pathogens similar to $B$. dolosa, such as $P$. aeruginosa and E. coli, are generally detected via flagellar interaction with TLR5 within several hours post-infection, leading to the eventual eradication of the invading bacterial population by host immune cells in healthy individuals.

To examine the potential roles of each flagellar type during B. dolosa pathogenesis, Dr. Yoder-Himes compared B. dolosa and P. aeruginosa in a mouse lung model of invasion. In this experiment, pools of C57BL/6 mice were inoculated intranasally with wildtype (WT), fliC mutant or lafA mutant strains of $B$. dolosa, while additional pools were inoculated with $P$. aeruginosa WT or fliC mutant strains as positive controls. Differences in recruitment of various immune response cells (i.e. macrophage, neutrophil, or myeloid suppressors), cytokine production, and bacterial survival over time were compared between the five B. dolosa and $P$. aeruginosa strains. Results from this experiment concluded that $P$. aeruginosa recruited more neutrophils and elicited the secretion of more overall pro-inflammatory cytokines than B. dolosa, and that B. dolosa persisted longer than P. aeruginosa in lung tissues (Supplemental Figures 3 and 4 respectively). Furthermore, when cytokines were elicited in response to B. dolosa, fliC and lafA mutants generally elicited a higher secretion of cytokines than did B. dolosa WT, while all B. dolosa strains elicited smaller cytokine secretions than $P$. aeruginosa strains. Three cytokines in particular, tumor necrosis factor alpha (TNF $\alpha)$, granulocyte/monocyte-colony stimulating factor (GM-CSF) and interleukin-6 (IL-6) were secreted largely in response to $P$. aeruginosa strains but at non-detectable levels in response to B. dolosa strains. 
While the evolutionary purpose behind $B$. dolosa possessing genes for two types of flagella may be explained by its many natural niches, the lack of an immune response in mice during $B$. dolosa infection relative to $P$. aeruginosa infection is more difficult to understand based on knowledge of the evolutionarily conserved TLR5 interaction with bacterial flagella. Therefore, an additional unpublished study by Dr. Yoder-Himes investigated the amino acid sequences of the B. dolosa FliC protein using Salmonella enterica FliC (whose crystal structure when complexed with TLR5 has been solved) as a comparative model in in silico experiments. Two strains of P. aeruginosa, PA14 and PAO1, as well as two additional Burkholderia strains, B. pseudomallei $1106 \mathrm{~b}$ and B. cenocepacia J2315 were also compared in the study. The results showed that critical residues within the FliC primary sequences corresponding to domains of flagellar interaction with TLR5 (entitled Domain A and Domain B) are very evolutionarily conserved in S. enterica and P. aeruginosa species (Supplementary Figure 6). However, the sequence differed at three critical residues in B. dolosa AU0158 and at two residues in the remaining two Bcc strains at interaction Domain A (Supplementary Figure 5). At interaction Domain B, B. dolosa AU0158 alone differed at a single critical residue. A loss of genetic conservation in these two regions could potentially lower TLR5's affinity for the flagellin ligand of B. dolosa during invasion, potentially explaining B. dolosa's observed evasion of the immune system in the mouse lung model.

To determine if the mouse lung results are representative of the immunogenic effects of these bacterial strains on human cells, my project examines the human host's immune response to the presence or absence of flagella by using Dr. Yoder-Himes' previously isolated WT (B. dolosa, P. aeruginosa) and previously crafted mutated (B. dolosa and P. aeruginosa $\Delta$ fliC, B. dolosa $\Delta l a f A$ ) bacterial strains in an in vitro model. Human cell lines directly related to those 
cells that are affected during CF bacterial infection were used as in vitro models of such pathogenesis, while each of the bacterial strains were cultured and individually introduced to a separate sample of human cells. An enzyme-linked immunosorbent assay (ELISA) for the detection of pro-inflammatory cytokines characteristic of the human immune response was used to calculate the concentration of pro-inflammatory cytokine secreted in response to each pathogen.

Because cytokine secretion in response to bacterial pathogens has been shown to fluctuate with time [17], this study also focuses on pro-inflammatory cytokine secretion as it varies temporally over twenty-four hours. In experimental models of infection the initial spike in pro-inflammatory cytokine secretion generally occurs at two hours post-infection as a response of the innate immune system, while at twenty-four hours post-infection a different composition of cytokines may be elicited in response to a particular pathogen [18]. Pro-inflammatory cytokines TNF $\alpha$ and IL-8 were chosen for assay. TNF $\alpha$ was chosen based on the large difference in its secretion between $B$. dolosa strains and $P$. aeruginosa strains observed in the mouse lung model. Although mice do not encode the gene for IL-8, this cytokine has been previously indicated as an important inflammatory mediator during $\mathrm{CF}$ pathogenesis by $P$. aeruginosa.

I have two hypotheses for this project. First, I hypothesize that B. dolosa species will elicit a lower immune response from human cells than P. aeruginosa based on data from the mouse lung experiment. Second, I hypothesize that relative to the wildtype $B$. dolosa strain, mutant strains will demonstrate a reduced ability to evade the human host's immune system. In other words, both flagella working in concert will be required for the bacteria to successfully invade host cells and evade the human immune response. Although counterintuitive, this 
hypothesis is based on the loss of amino acid sequence conservation in B. dolosa FliC at Primary Interaction Domain A and B for TLR5 binding, as well as the observed slight increase in cytokine secretion in response to $B$. dolosa fliC and lafA mutant strains when compared to $B$. dolosa WT in the mouse lung model. The results of this experiment will allow us to better understand how B. dolosa flagella interact with the human host during infection so that we can more effectively design therapeutics to combat this organism in the future.

\section{Materials and Methods}

\section{Bacterial Culture}

In order to examine the specific role of both types of B. dolosa flagella in the human immune response, B. dolosa WT was assayed alongside B. dolosa $\Delta$ fliC (polar flagella gene knockout) and B. dolosa $\triangle$ lafA (lateral flagella gene knockout). Concurrently, the model CF pathogen $P$. aeruginosa WT and an isogenic mutant, $P$. aeruginosa $\Delta f l i C$ were assayed as controls relevant to CF pathogenesis. For a positive control, the well-documented E. coli strain K12 was assayed. Therefore, all assayed species (B. dolosa, P. aeruginosa, and E. coli) were Gram-negative (express LPS) and encode at least one polar flagellum. TLR4 recognition of LPS and TLR5 recognition of flagella should thus result in similar immunogenicity amongst all assayed WT species, if no genetic variation exists in those genes encoding LPS and/or flagellar virulence traits.

As shown in Table 1, parental B. dolosa and P. aeruginosa strains were clinical isolates

from a CF patient and a burn wound patient, respectively. Isogenic B. dolosa mutants were previously generated by Damien Roux at Brigham and Women's Hospital in Boston, MA 
(unpublished) using SOE insertion [19]. The P. aeruginosa PAO1 $\Delta$ fliC mutant was created and verified by Massimo Merighi and Deborah Yoder-Himes (unpublished data).

Table 1: Bacterial Strain Information.

\begin{tabular}{|l|l|l|}
\hline Bacterial Background Strain & Strain Name & Description \\
\hline Pseudomonas aeruginosa & PAO1 WT & $\begin{array}{l}\text { Sequenced strain, wild-type, from burn } \\
\text { wound }\end{array}$ \\
\hline Pseudomonas aeruginosa & PAO1 $\Delta$ fliC & $\begin{array}{l}\text { PAO1 } \text { fliC mutant made via pEXG2 SOE } \\
\text { insertion [20] and counterselection on } \\
\text { sucrose plates, isolate \#1 }\end{array}$ \\
\hline Burkholderia dolosa & AU0158 & $\begin{array}{l}\text { Sequenced strain, wild-type, from CF } \\
\text { patient, outbreak at Children's Hospital } \\
\text { Boston. Index patient. }\end{array}$ \\
\hline Burkholderia dolosa & AU0158 $\triangle$ fliC & $\begin{array}{l}\text { AU0158 bearing a complete gene knockout } \\
\text { of fliC made by pEXKm5 [20] }\end{array}$ \\
\hline Burkholderia dolosa & AU0158 $\Delta$ lafA & $\begin{array}{l}\text { AU0158 bearing a complete gene knockout } \\
\text { of lafA made by pEXKm5 }\end{array}$ \\
\hline Escherichia coli & K12 & Commensal strain. \\
\hline
\end{tabular}

Quantitative Analysis of Bacterial Motility

Differences in swimming motility between $B$. dolosa WT and its isogenic mutants were confirmed by spotting a small aliquot $(5 \mu \mathrm{L})$ of each of bacterial strain grown to mid-log phase growth, normalized to an optical density at $600 \mathrm{~nm}$ (O.D.600) of 1.0, onto an LB agar plate containing 3\% agar ("swimming agar"). The next day, the diameters of each colony were measured via ruler. The average of five replicates was calculated and the significance determined by calculating one standard deviation of the data. 


\section{Qualitative Analysis of Bacterial Motility during Infection}

In order to better understand the roles of polar versus lateral flagella in B. dolosa, an additional invasion assay was performed and the motility of all six bacterial strains were qualitatively compared and contrasted. Bacterial strains were introduced to human U937 cells in a 96-well plate, which was then placed on an inverted light microscope for analysis. $P$. aeruginosa WT was aliquoted in columns one and two, $P$. aeruginosa $\Delta$ fliC in columns three and four, and so on for the remaining bacterial strains through twelve. Wells corresponding to each bacterial strain were filmed at varying bacterial dilutions for comparison.

\section{Tissue Culture Methods}

A549 Cell Line

The A549 human alveolar basal epithelial cell line was initially chosen for the invasion assay and ELISA for $\mathrm{TNF} \alpha$ as an adequate representation of human cells effected during pathogenicity in CF patients. Cells were frozen in liquid nitrogen prior to resuscitation. The cells were cultured in RPMI-1640 media supplemented with 10\% fetal bovine serum (FBS), and

were diluted every one-two days in order to maintain a density of approximately $2.0 \times 10^{5}$ cell/mL within a $\mathrm{T}_{75}$ or $\mathrm{T}_{150}$ flask. Because $\mathrm{A} 549$ is an adherent cell type forming a monolayer, 1X PBS was used to wash cells prior to detachment with $0.25 \%$ trypsin-EDTA before dilution.

\section{$\underline{\text { U937 Cell Line }}$}

The U937 human leukemic monocyte cell line was chosen as the next model cell line representing human cells affected during CF pathogenesis. These cells are genetically similar to human monocytes, a type of white blood cell that can secrete cytokines and differentiate to a 
larger phagocytic phenotype (macrophage) that also secretes cytokines and engulfs foreign pathogens. Similar to A549 culture, these cells were frozen in liquid nitrogen prior to resuscitation and grown in RPMI-1640 media with 10\% FBS supplement. Cells were diluted every two-three days in order to maintain a density of approximately $2.0 \times 10^{5} \mathrm{cell} / \mathrm{mL}$ within a $\mathrm{T}_{75}$ or $\mathrm{T}_{150}$ flask. Cells were measured via hemocytometer under the light microscope. As a suspension culture, no additional chemicals were needed for dilution purposes. However, it was observed that random cell apoptosis in certain monocytes appeared to activate neighboring monocytes to convert to macrophages, which are in charge of engulfing foreign particles and cellular debris. Once converted to macrophage cells no longer divide and the population can quickly diminish. In order to prevent the conversion of all monocytes within the culture to macrophage, the cells were subjected to centrifugation at $1000 \times g$ for 3 minutes and the supernatant removed prior to each dilution. This proved to remove the majority of cellular debris, and effectively resulted in a larger population of healthy, dividing monocytes.

\section{PMA Optimization in U937 Cells}

For certain experiments, U937 cells were chemically differentiated to macrophage prior to invasion. Phorbol myristate acetate (PMA) is a chemical agent routinely used in monocyte activation by specifically activating the NF-אB pathway in monocytes [21]. However, literature values citing optimal PMA concentrations for the differentiation of monocytes vary widely [2224]. It was therefore necessary to optimize PMA for differentiation of U937 cells. The cells were grown to a density of $1.0-2.0 \times 10^{5}$ cells $/ \mathrm{mL}$. Cells were measured via hemocytometer under the light microscope. An aliquot $(100 \mu \mathrm{L})$ of eukaryotic cells were added to a 96-well tissue culture plate in rows A-H, columns 1-3 only (Table 3 in Results). A stock solution (1 
$\mathrm{mg} / 1 \mathrm{~mL}$ ) of PMA was prepared in dimethyl sulfoxide (DMSO) and then diluted in doubledistilled water $\left(\mathrm{ddH}_{2} \mathrm{O}\right)$ to $250 \mathrm{pg} / \mathrm{mL}, 100 \mathrm{pg} / \mathrm{mL}$, and $50 \mathrm{pg} / \mathrm{mL}$. An aliquot $(10 \mu \mathrm{L})$ of each dilution was added to quadruple replicate wells to a final volume of $110 \mu \mathrm{L}$ per well. Negative controls were represented by quadruple replicates of DMSO diluted 1:400 in $\mathrm{ddH}_{2} \mathrm{O}$, RPMI1640, and $\mathrm{ddH}_{2} \mathrm{O}$ alone. The cells were observed daily for three days. To estimate the percent differentiation, phenotypic differences in cells (i.e. monocytes are significantly smaller than macrophages) were noted.

\section{PMA-Induced Differentiation of U937 Cells}

For those experiments in which U937 cells were allowed to chemically differentiate to macrophage, a solution of PMA $(100 \mathrm{pg} / \mathrm{mL})$ was added to $10 \%$ of the total final volume of tissue culture medium $(100 \mu \mathrm{L})$. Experiments in which approximately $50 \%$ of U937 cells differentiated to macrophage following twenty-four hours of PMA exposure are shown.

\section{Invasion Assays}

Each of the six bacterial strains were grown separately overnight in $5 \mathrm{~mL}$ LB liquid on a roller drum at $37^{\circ} \mathrm{C}$. On the day of the invasion, cultures were removed from incubation and were diluted to an O.D.600 of approximately 0.1 in $125 \mathrm{~mL}$ Erlenmeyer flasks, and incubated at $37^{\circ} \mathrm{C}$ with shaking $(300 \mathrm{rpm})$ for several hours. Bacteria were then harvested during optimal growth (O.D.600 of $\sim 0.8$, or mid-log phase). When each culture reached an O.D.600 of approximately 0.8 , it was harvested and cooled over ice to discourage further growth. An aliquot $(3 \mathrm{~mL})$ of each bacterial strain were centrifuged; the supernatant was discarded and replaced with RPMI-1640 tissue culture media in preparation for invasion. A volume (900 $\mu \mathrm{L})$ of RPMI-1640 
was added to rows $\mathrm{A}, \mathrm{C}, \mathrm{D}, \mathrm{E}, \mathrm{F}, \mathrm{G}$ and $\mathrm{H}$ of a tall-welled plate. An aliquot $(1 \mathrm{~mL})$ of each bacterial strain was added in duplicate columns across row B, such that P. aeruginosa WT was aliquoted in columns one and two, $P$. aeruginosa $\Delta f l i C$ in columns three and four, and so on (Supplemental Table 1). Each strain was then diluted in a ten-fold series from the top concentration $\left(\sim 10^{8}\right.$ bacterial cells $\left./ \mathrm{mL}\right)$ in row $\mathrm{B}$, ending in row $\mathrm{H}\left(\sim 10^{2}\right.$ bacterial cells $\left./ \mathrm{mL}\right)$.

While the bacterial cultures were growing to log phase, human cells (A549 or U937) were diluted to a target density of $1.0-2.0 \times 10^{5}$ cells $/ \mathrm{mL}$. Aliquots $(100 \mu \mathrm{L})$ of human cells were distributed in each well of a 96-well tissue culture plate and incubated until bacterial growth was finished. An aliquot $(100 \mu \mathrm{L} /$ well) from the 96 -welled bacterial culture plate was transferred directly to the corresponding wells of the 96-welled tissue culture plate, marking time zero $\left(\mathrm{T}_{0}\right)$ of the invasion. The plate was then incubated at $37^{\circ} \mathrm{C}$ and $5 \% \mathrm{CO}_{2}$ until the appropriate time had elapsed (i.e. two hours for the two hour post-infection ELISA).

\section{ELISA for Human TNF $\alpha$ and IL-8}

Enzyme-linked immunosorbent assays (ELISAs) were performed following each invasion assay. Human pro-inflammatory cytokines tumor necrosis factor alpha (TNF $\alpha)$ and interleukin 8 (IL-8) were surveyed using Ready-Set-Go! ELISA kits (eBioscience). The capture antibody for the assayed cytokine was added to a Corningstar 96-well high-protein binding plate on the eve of the ELISA and left overnight at $4{ }^{\circ} \mathrm{C}$. The following day, the wells were blocked using assay diluent to reduce non-specific interactions. After the appropriate incubation period, a tissue culture plate was removed from incubation and centrifuged at $800 \times g$ for 4 minutes in

order to separate the maximal concentration of cytokine into the supernatant layer. On the ELISA plate, a standard curve was added to row A, columns 1-8 with a two-fold dilution series 
of detectable concentrations of the appropriate cytokine (provided by ELISA kit manufacturer). An aliquot $(100 \mu \mathrm{L})$ of the invasion assay supernatant was then transferred to the ELISA plate in rows $\mathrm{B}-\mathrm{H}$ and incubated overnight at $4^{\circ} \mathrm{C}$ for maximal sensitivity.

The following day a detection antibody tagged with biotin was added to the ELISA plates and incubated at room temperature. Fluorescence was achieved by adding avidin horseradish peroxidase (avidin-HRP), the avidin component of which binds biotin with high affinity and, in the presence of a substrate, catalyzes a colorimetric reaction. This resulted in the quantifiable emission of blue light corresponding to the number of bound cytokine molecules in each well. Finally, $2 \mathrm{~N} \mathrm{H}_{2} \mathrm{SO}_{4}$ was added to stop the reaction and caused detectable cytokine to turn yellow. The absorbance of each well was then read in a spectrophotometer at $450 \mathrm{~nm}$ and $570 \mathrm{~nm}$. The absorption values at $570 \mathrm{~nm}$ were subtracted from those at $450 \mathrm{~nm}$, and the difference was used in subsequent calculations per the manufacturer's instructions. The absorption values from the standard curve were plotted against the known concentrations of cytokine from the dilution series, and a line of best fit was calculated. The linear equation of best fit could then be used to

determine the concentration of cytokine per well, according to Beer's Law. Columns 9-10 of row A contained RPMI-1640 alone, and served as background controls (Supplemental Table 1). Values from negative control wells were averaged and subtracted from the values for the experimental wells.

\section{Statistical Methodology}

Linear regressions for standard curves and standard deviations of replicate ELISA samples were calculated in Microsoft Excel. 


\section{Results}

\section{Verification of motility of $B$. dolosa flagellar mutants}

B. dolosa WT and mutant strains were plated on swimming agar to confirm the success of fliC and lafA gene knockouts. It was assumed that capable bacteria would express flagella for movement in the less viscous medium, and that WT and mutant strains would grow at the same rate (confirmed in unpublished study by Dr. Yoder-Himes). Differences in migration distance between WT and isogenic mutants after overnight growth should confirm a successful gene knockout in mutant strains. Based on previous data, B. dolosa WT is known to express both flagellar types in varying environmental conditions, and was therefore expected to migrate a greater distance than a flagellar mutant. Thus I expected the $\Delta$ fliC mutant to migrate the smallest distance. Since the lateral flagella are not known to play much of a role in swimming motility in other organisms, I expected the migration of the lafA mutant to be similar to that of wildtype B. dolosa.

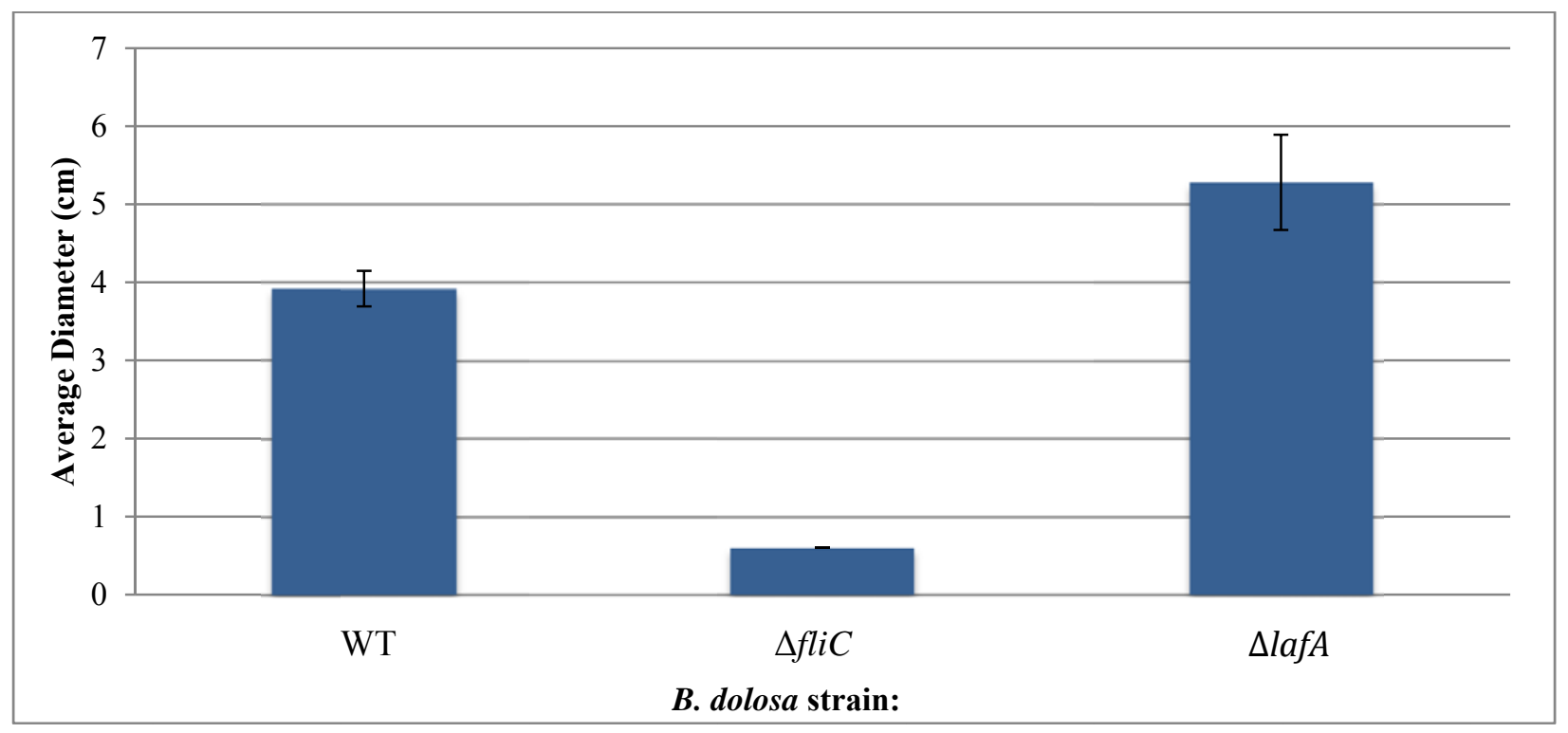

Figure 1: Average diameter of $B$. dolosa colonies when compared over five trials. Error bars represent one standard deviation from the five trials. B. dolosa colony diameters were determined with accuracy to the hundredth decimal place. 
B. dolosa WT showed a mean swimming diameter of $3.92 \pm 0.23 \mathrm{~cm}$ (Figure 1, Supplementary Table 2). B. dolosa $\Delta$ fliC, as expected, showed a very consistent, small swimming diameter of $0.60 \mathrm{~cm}$ in all five replicates. Lastly, the $\Delta l a f A$ mutant strain surprisingly yielded a significantly higher swimming diameter of $5.28 \pm 0.61 \mathrm{~cm}$ when compared to WT. This suggests that the lateral flagella may play an inhibitory role in swimming motility. Additionally, the difference in colony diameters for the WT and the SlafA mutant colony diameters was much less than the difference between WT and $\Delta$ fliC mutant colony diameters, supporting the idea that FliC plays a greater role in swimming motility than LafA.

\section{The motility of bacterial strains in tissue culture medium}

Motility in the six bacterial strains during infection of human cells was compared under an inverted light microscope immediately following invasion to determine how the strains moved under tissue culture conditions. P. aeruginosa WT and fliC mutant strains as well as E. coli K12 served as positive controls and for comparisons with all three strains of $B$. dolosa.

Table 2: Qualitative comparison of bacterial motility during invasion of U937 cells observed on an inverted light microscope at $400 \mathrm{X}$ magnification.

\begin{tabular}{|c|c|}
\hline Strain & Motility Observations \\
\hline P. aeruginosa WT & Long, rapid runs; some tumbles \\
\hline P. aeruginosa $\Delta$ fliC & No observable movement \\
\hline B. dolosa WT & $\begin{array}{c}\text { Some long runs, many short runs; more } \\
\text { tumbles compared to P. aeruginosa WT }\end{array}$ \\
\hline B. dolosa $\Delta f l i C$ & $\begin{array}{c}\text { Some short, slow runs; long filamentous } \\
\text { chains of cells forming and swarming }\end{array}$ \\
\hline B. dolosa $\Delta l a f A$ & Similar to B. dolosa WT, with shorter runs and \\
& more tumbles \\
\hline E. coli K12 & Rapid runs and frequent tumbles \\
\hline
\end{tabular}


As expected, wildtype P. aeruginosa and E. coli strains showed rapid movement in tissue culture medium in the presence of human cells (Table 2). Without the polar flagellum, $P$. aeruginosa $\triangle f l i C$ was rendered completely immobilized in RPMI-1640 tissue culture medium. It was expected that $B$. dolosa $\Delta$ fliC would similarly be unable to swim effectively, but that the presence of lateral flagella could attenuate this effect to some degree. This indeed was observed, as certain cells within the B. dolosa $\Delta$ fliC mutant population appeared to swim in slow, short runs compared to the isogenic WT (Table 2). Additionally, many long, motile, filamentous chains of B. dolosa $\triangle f l i C$ cells appeared to form during invasion. The deletion of the fliC gene may have resulted in an inherent signal for these cells to form linkages, as linking of cells and shedding of polar flagella occurs naturally during biofilm formation.

These results revealed that $B$. dolosa $\Delta f l i C$ is capable of movement within tissue culture medium during invasion of human cells, while $P$. aeruginosa $\Delta$ fliC is not. This suggests that $B$. dolosa lateral flagella are expressed in the absence of the polar flagellum, and that these flagella do allow for some degree of bacterial motility in a liquid environment. Lateral flagella may have also assisted in cell-cell linkages observed amongst $B$. dolosa $\Delta$ fliC cells. The motility observed in linked cells more closely resembled swarming motion, which is generally attributed to lateral flagellar motion.

\section{TNF $\alpha$ production in A549 cells in response to B. dolosa strains}

In order to quantify the immune response of human cells to the six bacterial pathogens discussed in this study, A549 alveolar basal epithelial cells were infected with one of each bacterial strain and subsequently assayed for $\mathrm{TNF} \alpha$ secretion after two or twenty-four hours of incubation. The A549 cell line had been previously assayed for TNF $\alpha$ secretion in response to 
the same six bacterial strains with little success (unpublished, Dr. Yoder-Himes). Therefore, this experiment aimed to confirm or reject these unpublished results. Data from one replicate experiment is shown in Figure 2.

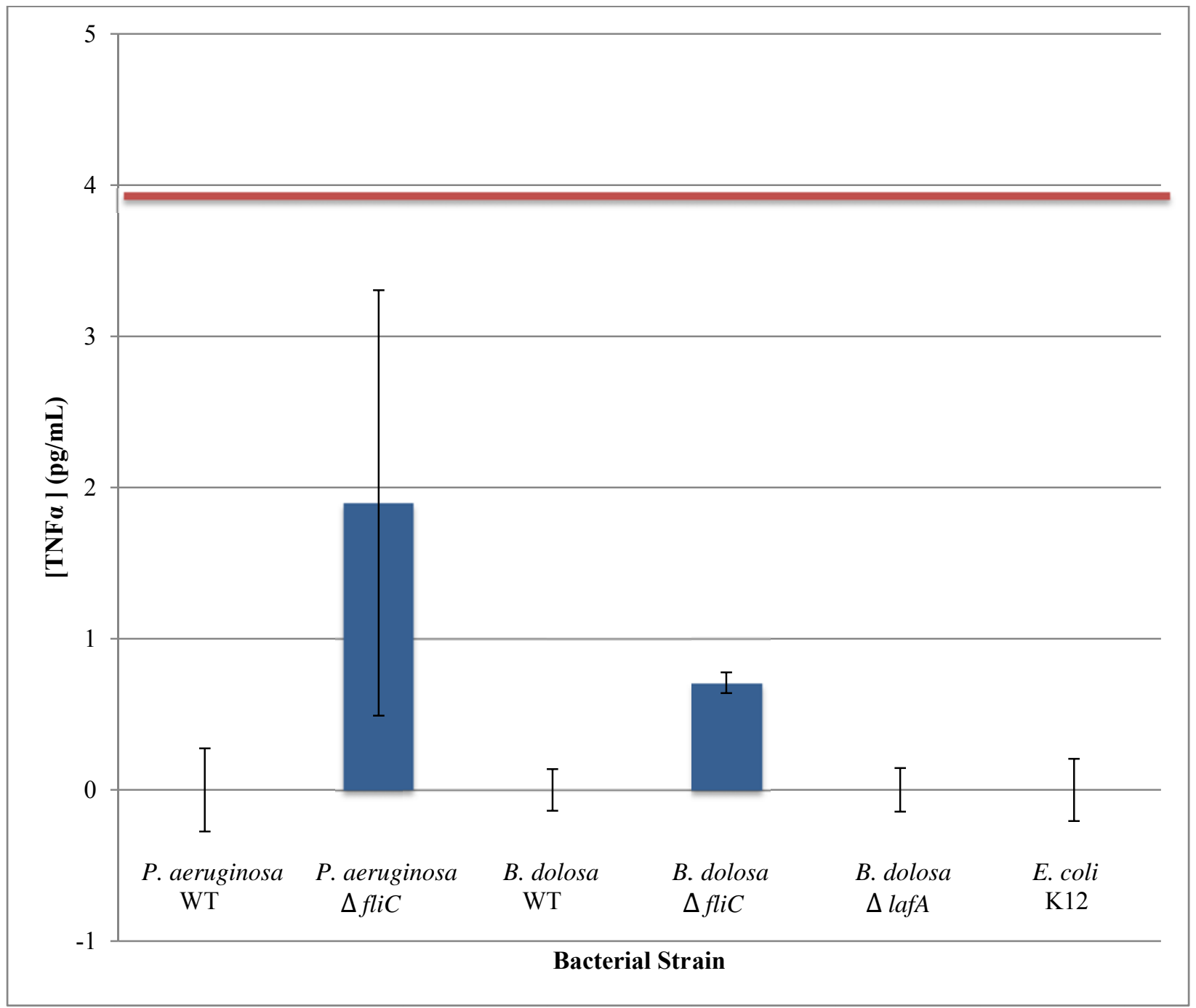

Figure 2: Pro-inflammatory cytokine TNF $\alpha$ secretion in A549 lung epithelial cells in response to bacterial pathogens. For each group of strains ( $P$. aeruginosa strains, B. dolosa strains, and E. coli K12), the concentration of bacteria resulting in the greatest overall secretion of TNF $\alpha$ was calculated to account for the different infectious doses of these organisms. The values for all strains fell below the limit of detection for this test. Strains showing a value of zero were not above the background noise. Error bars represent one standard deviation calculated from duplicate samples for each bacterial strain. The horizontal bar (red) designates the limit of detection for the ELISA kit $(4 \mathrm{pg} / \mathrm{mL})$.

Although Figure 2 appears to show evidence for low levels of TNF $\alpha$ secretion in response to the fliC mutants, the detected cytokine levels fell below the detectable concentration 
of cytokine specified by the ELISA kit manufacturer, and thus bear no statistical significance. These results confirmed what Dr. Yoder-Himes observed during previous studies. The experiment was repeated four times, but no cytokine was detected in any sample wells during any replicate experiment. The equation of best fit for the standard curve bore a linear slope with an R-value of $>0.98$ for each replicate experiment, signifying that the steps of the ELISA were performed correctly (Supplemental Figure 8).

After confirming Dr. Yoder-Himes' previous results using A549 cells, it was assumed that the A549 cell line was not fit for further experimentation in this project. A new cell line, the U937 leukemic monocyte lymphoma cell line, was available and chosen for further study due to its similarities to active cells of the human immune response. Two replicate experiments assaying for TNF $\alpha$ were initially performed using U937 cells, with the same results found in A549 cells. This data was therefore not included in this thesis. A new cytokine of interest, IL-8, was chosen as the next assayed cytokine due to its known role in the CF inflammatory response.

\section{IL-8 production in undifferentiated $\mathrm{U} 937$ cells in response to $B$. dolosa strains}

Among all experiments assaying for IL-8 secretion in U937 cells, data from three ELISA plates were considered successful based on a) linearity of the standard curve and b) lack of any form of observable contamination upon visual inspection (i.e. strains plated on agar showed no variation in colony size/composition; wells corresponding to tissue culture medium alone showed no cloudiness). Data from two of these replicate assays are shown here, corresponding to undifferentiated U937 cells at two hours (Figure 3) and twenty-four hours (Figure 4) postinfection. 


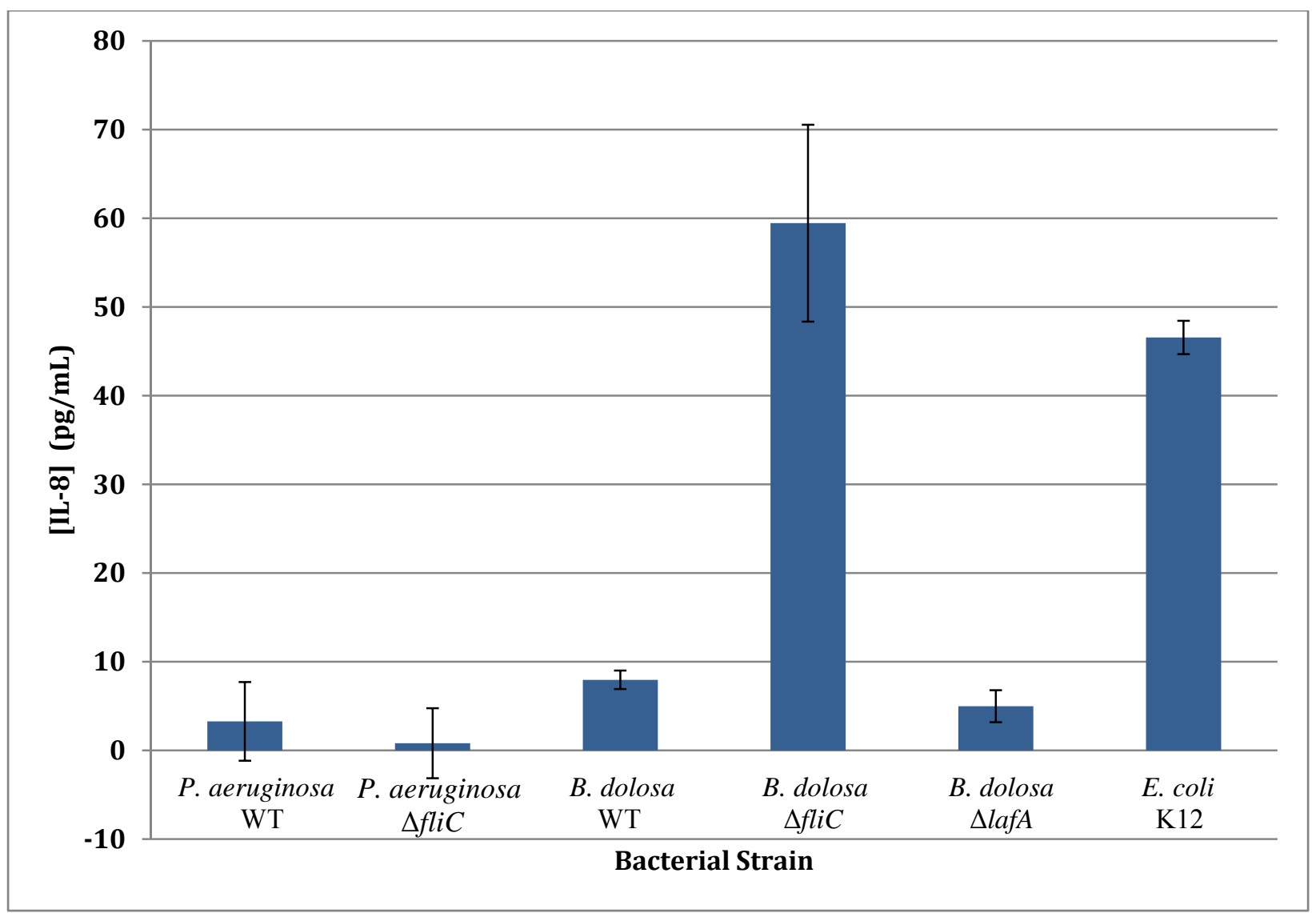

Figure 3: Pro-inflammatory cytokine IL-8 production in undifferentiated human U937 cells in response to bacterial pathogens. IL-8 levels were measured by ELISA assay of U937 macrophage-like cells 2 hours post-infection with a ten-fold series of bacterial concentrations. The optimal IL-8 expression for each wild-type strain is shown along with the IL-8 production from isogenic mutants at the same concentration. E. coli $\mathrm{K} 12$ was used as a positive control. Error bars represent one standard deviation of the data from duplicate samples in the 96-well plate.

At two hours post-infection, undifferentiated U937 cells secreted significantly more IL-8 in response to $B$. dolosa $\Delta$ fliC than any other bacterial strain, with an average IL- 8 concentration of $59.5 \mathrm{pg} / \mathrm{mL}$. B. dolosa WT and B. dolosa $\Delta$ lafA elicited minimal responses when compared to B. dolosa $\Delta$ fliC and E. coli K12; interestingly, both P. aeruginosa species also elicited minimal responses, although it has been shown in previous literature that $P$. aeruginosa species are fairly potent stimulators of pro-inflammatory cytokine secretion. This is likely due to expedient cell death following invasion: wells containing $P$. aeruginosa species tended to turn yellow shortly after invasion, which I have found to signify massive cell death upon investigation under the 
microscope. Nevertheless, the $P$. aeruginosa species were present in the same dilution series as the other bacterial strains, and the most dilute wells should have corresponded to a low multiplicity of infection (MOI) and thus a low mortality in infected human cells.

The positive control E. coli K12 elicited a response comparable to the response elicited by the B. dolosa fliC mutant. E. coli was capable of expressing both a polar flagellum and LPS, while B. dolosa $\triangle$ fliC likely expressed a greater surface area of LPS (relative to its isogenic WT strain) in the absence of its polar flagellum. Thus, the observed greater secretion of cytokine in response to B. dolosa $\triangle$ fliC could be explained by a greater recognition of LPS by TLR4. Another possibility is that the multiple, lateral flagella of $B$. dolosa $\Delta$ fliC were recognized by TLR5 to a greater degree than the E. coli polar flagellum.

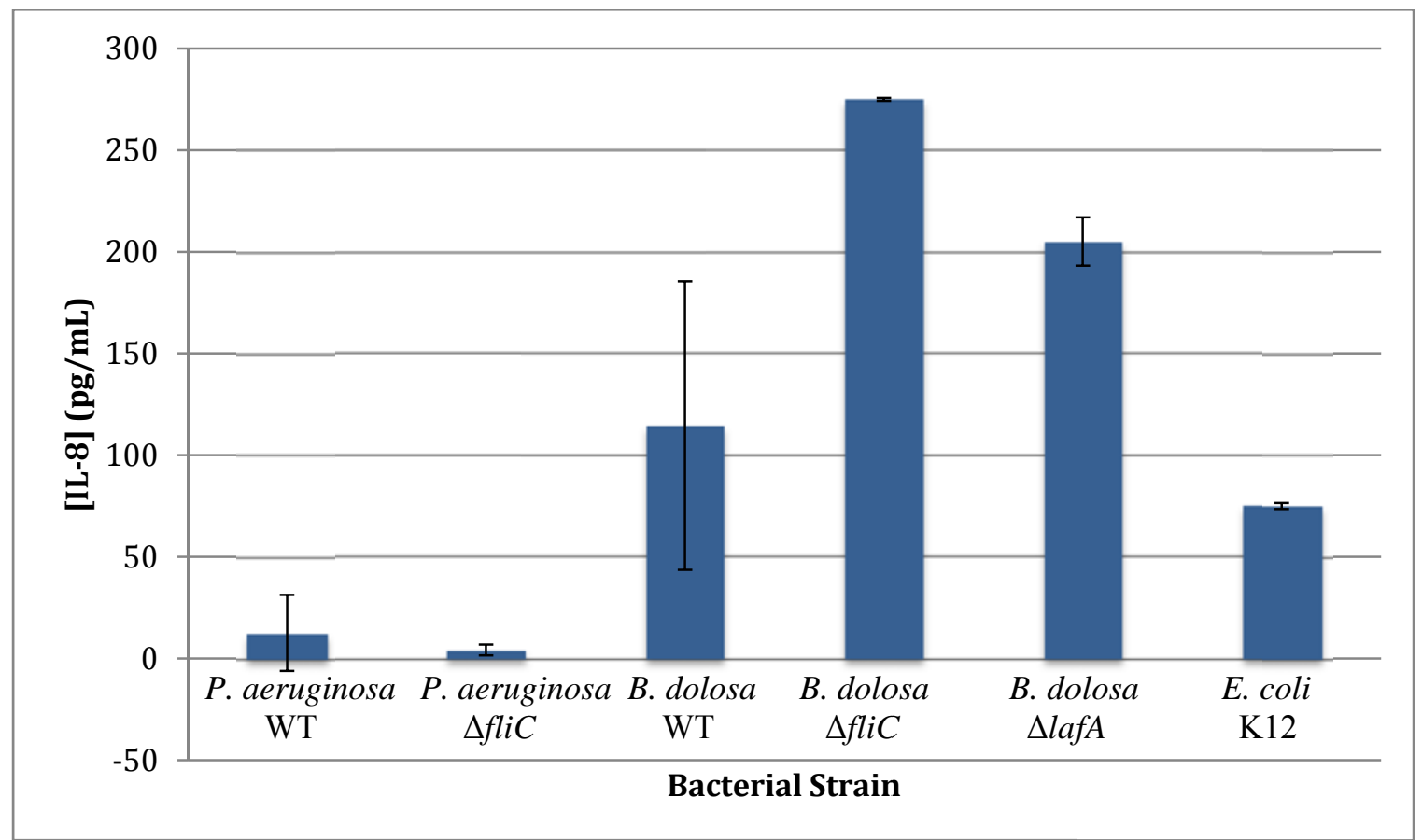

Figure 4: Pro-inflammatory cytokine IL-8 production in undifferentiated human U937 cells in response to bacterial pathogens. Interleukin 8 levels were measured by ELISA assay of U937 macrophage-like cells 24 hours post-infection with a ten-fold series of bacterial concentrations. The optimal IL-8 expression for each wild-type strain is shown along with the IL-8 production from isogenic mutants at the same concentration. E. coli K12 was used as a positive control. Error bars represent one standard deviation of the data from duplicate experiments. 
At twenty-four hours post-infection in undifferentiated U937 cells, cytokine secretion in response to all species increased greatly. This finding is possibly a function of additional PAMP recognition (i.e. toxins and foreign nucleic acids) by intracellular TLRs in addition to continued recognition of extracellular PAMP ligands. B. dolosa $\Delta$ fliC elicited the greatest response form human cells, with a mean IL-8 concentration of $275 \mathrm{pg} / \mathrm{mL}$ (Figure 4). Levels of IL-8 secretion in response to B. dolosa $\Delta$ lafA surpassed those in response to E. coli after twenty-four hours. However, most U937 cells in wells containing E. coli had apoptosed at twenty-four hours postinfection, which could explain the relatively low levels of IL-8 secretion in response to this pathogen. Similar to results at two hours post-infection, P. aeruginosa strains elicited minimal responses relative to the four other bacterial strains, again likely due to observed human cell death.

These findings reinforced the two hours post-infection results: B. dolosa $\Delta$ fliC elicited the highest secretion of cytokines from human cells relative to all other tested strains. Clearly, the absence of the polar flagellum in this $B$. dolosa strain allows for greater immune system recognition and immunogenicity in human cells. At this time point, B. dolosa WT elicited the smallest immune response relative to the three B. dolosa strains tested, suggesting that the lateral flagella of B. dolosa might be necessary for evasion of the human immune system after time has allowed for intracellular invasion of host cells. This suggestion is partially supported by knowledge that lateral flagella are necessary for intracellular motility in other well-studied pathogens. 


\section{Time-dependent IL-8 production in U937 undifferentiated cells in response to B. dolosa strains}

In order to visually compare the temporal fluctuation of IL-8 secretion in undifferentiated U937 cells from two to twenty-four hours post-infection, I re-analyzed my previous data.

B. dolosa $\Delta$ fliC and E. coli $\mathrm{K} 12$ were the only two species to elicit a significant response from undifferentiated U937s at two hours post-infection (Figure 5). However, from this model alone it appears that B. dolosa species experienced the greatest percent increase in IL-8 secretion when compared to P. aeruginosa and E. coli species. Of note, B. dolosa is the only species

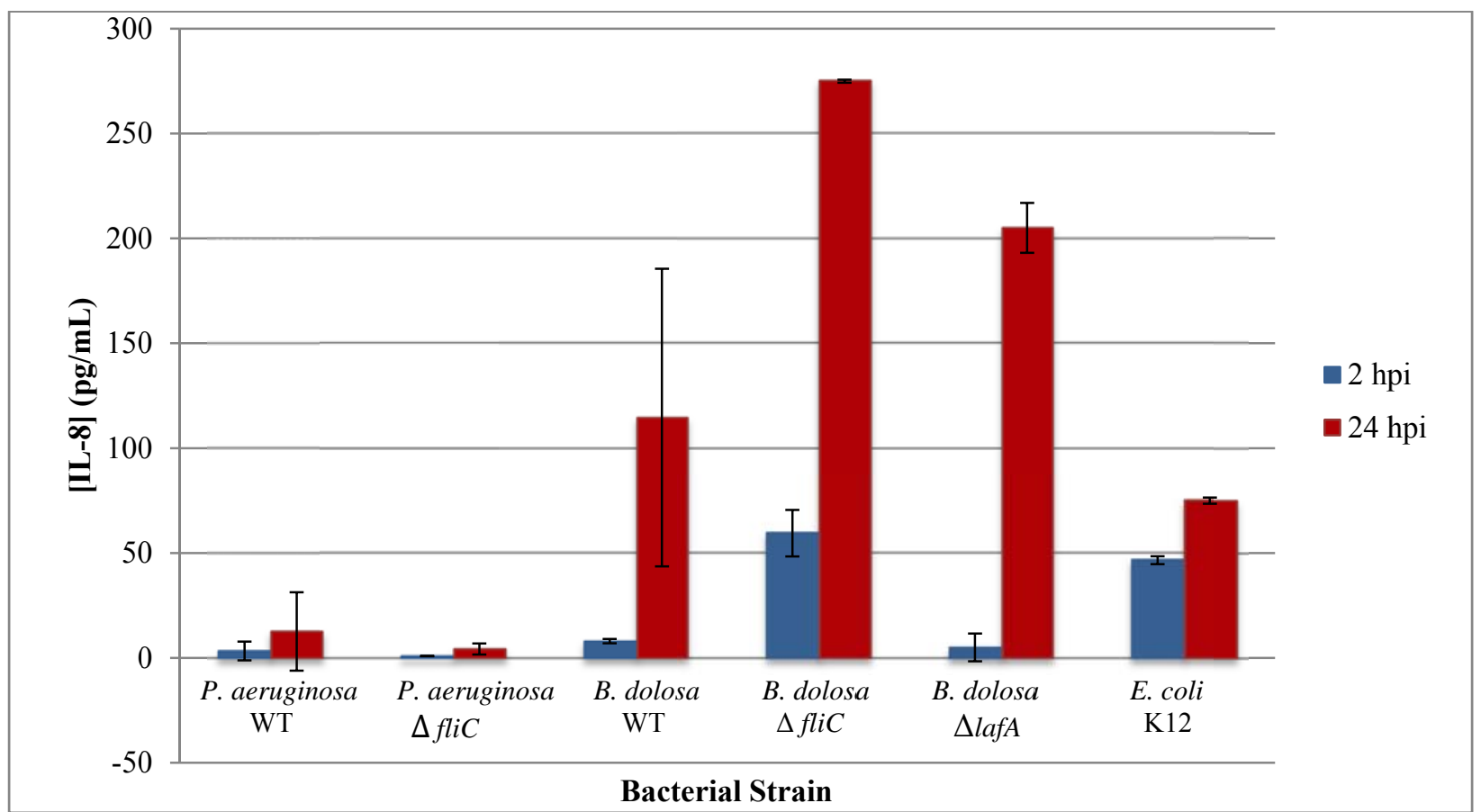

Figure 5: The variation in IL-8 secretion from undifferentiated U937 cells observed over time (2-24 hpi). B. dolosa $\Delta$ fliC and E. coli $\mathrm{K} 12$ were the only two species to elicit a large response from human cells at 2 hours post-infection.

among the six bacterial strains tested that is an intracellular pathogen, which could explain the continued increase in cytokine secretion elicited by this species. P. aeruginosa and E. coli species are known to secrete toxins to kill host cells, which could explain the minimal increase in cytokine secretion in response to these pathogens with time. 


\section{PMA optimization}

Phorbol myristate acetate (PMA) is a chemical agent routinely used to chemically differentiate monocytes into activated macrophage, though literature sources suggest a wide range of concentrations to be used. The optimal concentration of PMA for chemical differentiation of U937 cells was determined prior to U937 use in invasion assay or ELISA. A portion of a 96-well tissue culture plate was used for this experiment (Table 3). Three concentrations of PMA were added to equivalent numbers of U937 cells and were qualitatively assessed for three days. The PMA concentration resulting in the highest percent differentiation of U937 cells with minimal cell death within seventy-two hours was considered optimal.

\begin{tabular}{|c|c|c|c|}
\hline & \multicolumn{3}{|c|}{ [PMA] (pg/mL) } \\
\cline { 2 - 4 } & $\mathbf{1}$ & $\mathbf{2}$ & $\mathbf{3}$ \\
\hline A & 250 & 50 & DMSO \\
\hline B & 250 & 50 & DMSO \\
\hline C & 250 & 50 & DMSO \\
\hline D & 250 & 50 & DMSO \\
\hline E & 100 & RPMI & ddH2O \\
\hline F & 100 & RPMI & ddH2O \\
\hline G & 100 & RPMI & ddH2O \\
\hline H & 100 & RPMI & ddH2O \\
\hline
\end{tabular}

Table 3: Plate layout for PMA optimization using U937 cells. Each well contained an aliquot of $1.8 \times$ $10^{5}$ cells $/ \mathrm{mL}$ U937 cells. Experimental wells are denoted by number $(250,100,50)$ corresponding to concentration of PMA added. Negative control wells included plain tissue culture medium (RPMI-1640), DMSO alone (PMA dissolution solvent) and double-deionized $\mathrm{H}_{2} \mathrm{O}$ (PMA serial dilution solvent).

The results of the PMA optimization experiment showed that $100 \mathrm{pg} / \mathrm{mL}$ was the optimal concentration for U937 differentiation under laboratory conditions, with an incubation time between one and two days for optimal percent differentiation of over 50\%. Cells treated with $250 \mathrm{pg} / \mathrm{mL}$ PMA died within twenty-four hours; cells treated with $50 \mathrm{pg} / \mathrm{mL}$ PMA remained largely undifferentiated after three days, and were considered unsuccessful. 


\section{IL-8 production in differentiated cells in response to $B$. dolosa strains}

U937 cells were chemically induced to differentiate for twenty-four hours prior to invasion by bacterial species. Chemically differentiated cells are "activated" as the macrophage phenotype, which is responsible for secreting large quantities of cytokines and engulfing pathogens via phagocytosis. Therefore, it was expected that IL-8 secretion would rise in response to all pathogens during this experiment. Within the time limitations of this study, only one plate representing differentiated U937 cells after twenty-four hours of infection was successful (Figure 6).

At twenty-four hours post-infection, differentiated U937 cells secreted greater amounts of cytokine in response to all bacterial pathogens, when compared to the same results at twentyfour hours post-infection in undifferentiated cells. A small but significant increase in cytokine secretion in response to $B$. dolosa $\Delta$ fliC compared to $B$. dolosa WT was again observed in differentiated U937 cells as it was in undifferentiated U937 cells, providing further evidence that the polar flagellum of $B$. dolosa does increase the pathogen's ability to evade the human immune response.

IL-8 secretion was greatly increased for $P$. aeruginosa species in differentiated cells. The pre-activation of U937 cells towards cytokine secretion prior to invasion with bacteria is the most likely cause of this observation. Standard deviations for both $P$. aeruginosa species were much greater than those calculated for B. dolosa and E. coli species. This was possibly the result of contamination of the bacterial culture (although no contamination was visually observed) or variance in the health of human cells between the replicate wells. Therefore, this experiment must be repeated in the future to observe statistically significant variations in average cytokine secretion in response to each bacterial pathogen in differentiated cells (See Supplemental 


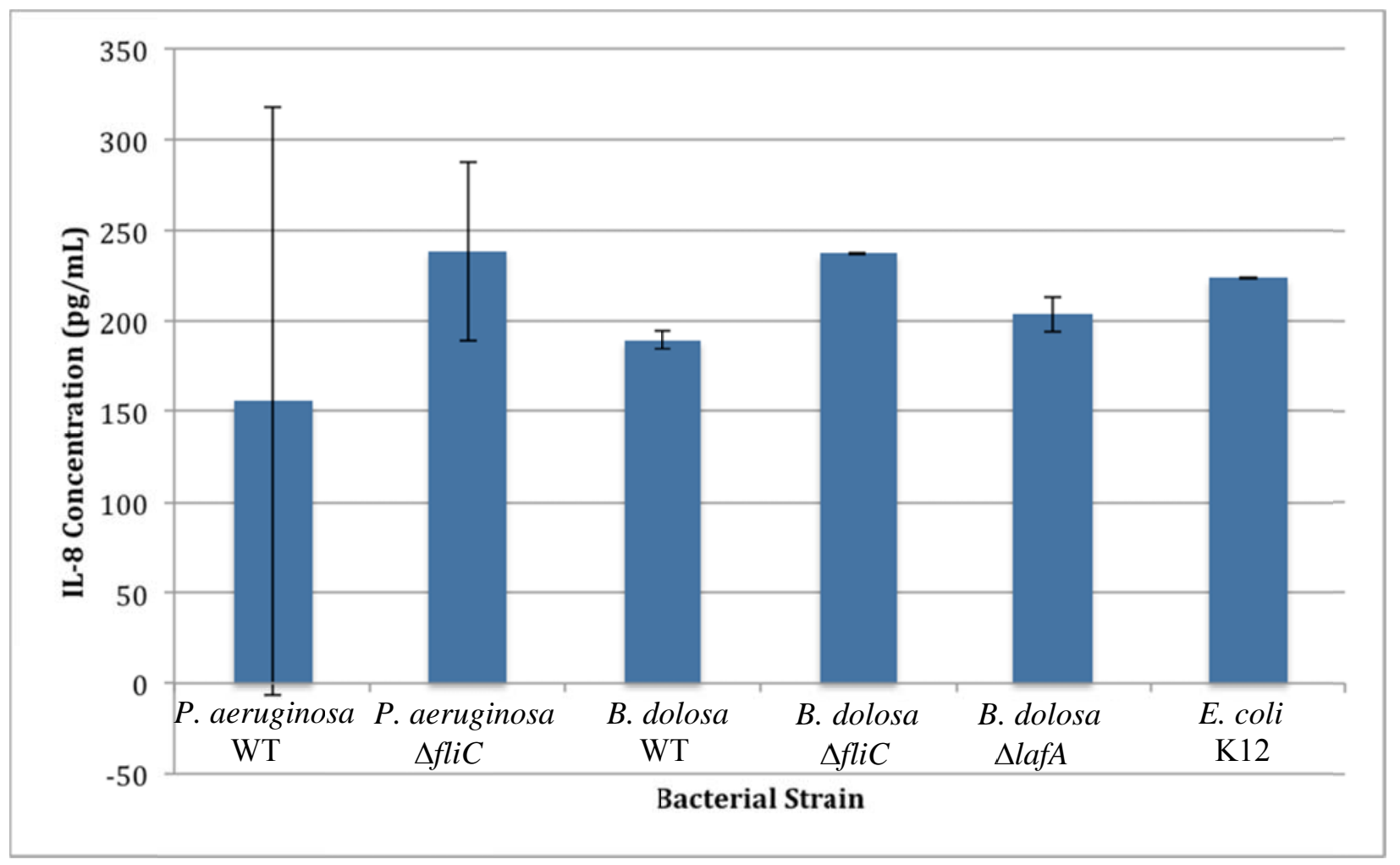

Figure 6: Pro-inflammatory cytokine IL-8 production in differentiated human U937 cells in response to bacterial pathogens. Interleukin 8 levels were measured by ELISA assay of U937 macrophage-like cells 24 hours post-infection with a ten-fold series of bacterial concentrations. The optimal IL-8 expression for each wild-type strain is shown along with the IL-8 production from isogenic mutants at the same concentration. E. coli K12 was used as a positive control. Error bars represent one standard deviation of the data from duplicate experiments.

Figures 9-11 for IL-8 ELISA standard curves).

\section{Comparing IL-8 secretion from undifferentiated to differentiated U937 cells}

\section{in response to $B$. dolosa strains}

A comparison was performed to illuminate any differences in response to bacterial pathogens between naïve immune cells (undifferentiated) versus activated immune cells (differentiated), both of which would encounter pathogens in vivo. Naïve U937 cells are representative of the monocyte phenotype, while activated U937 cells represent the macrophage phenotype. 
I hypothesized that chemically differentiated U937 cells would secrete IL-8 in larger amounts than undifferentiated U937 cells. In order to examine the validity of this hypothesis, two ELISA experiments were performed under identical conditions, one containing undifferentiated U937 cells and one containing differentiated U937 cells, were compared at the same time post-infection (24 hpi) (Figure 7 and Supplemental Table 3).

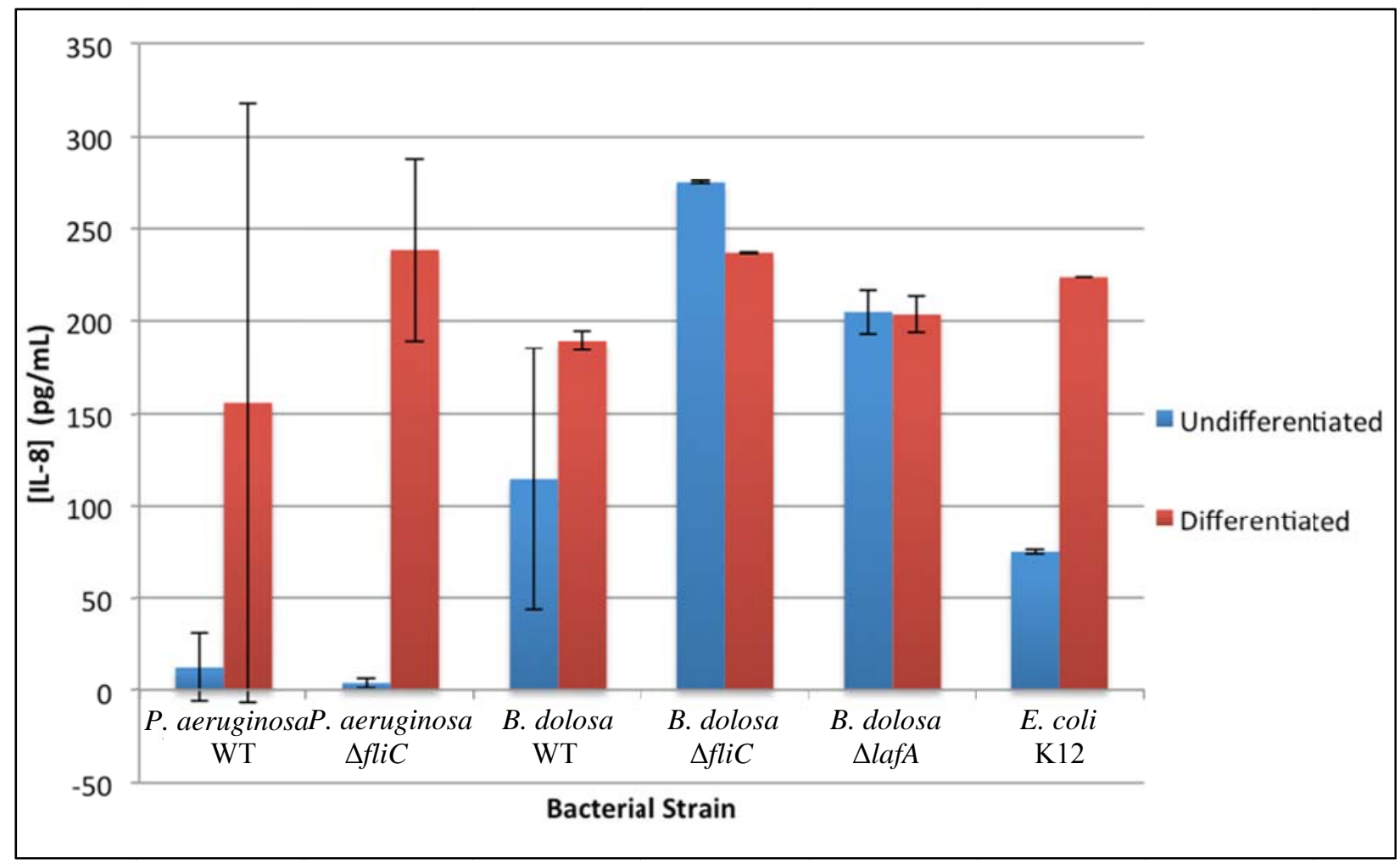

Figure 7: Comparison of IL-8 secretion levels between differentiated and undifferentiated U937 cells at 24 hours post-infection.

All species elicited greater secretions of cytokines from differentiated U937 cells when compared to undifferentiated U937 cells. This data confirms that there is a difference in cytokine secretion between naturally and chemically differentiated U937 cells when introduced to bacterial pathogens, although the reason for this requires further research. Additionally, the amount of cytokine secreted from differentiated cells fell within a similar range in response to all six bacterial pathogens. However, this comparison shows a significantly greater percent increase in IL-8 secretion when changing from undifferentiated to differentiated U937 cells for the $P$. 
aeruginosa $\Delta$ fliC strain and E. coli K12. However, this same effect was not observed when comparing undifferentiated to differentiated U937 cell IL-8 response for the B. dolosa strains.

The marginal changes in IL-8 secretion from undifferentiated to differentiated U937 cells in response to $B$. dolosa species were not significant in the WT and lafA mutant strains; however, the effect of differentiating the U937 cells yielded a significantly lower IL-8 production in the fliC mutant. The small but significant differences in cytokine secretion between undifferentiated and differentiated U937 cells in response to the three B. dolosa strains suggests that this species interacts similarly with the monocyte and macrophage phenotype, while the same might not be true for P. aeruginosa and E. coli species. However, because of the variance observed in this experiment (particularly for the P. aeruginosa WT strain), additional replicate experiments must be conducted to validate these data.

\section{Discussion}

The A549 human alveolar basal epithelial cell line that was initially selected as the in vitro human cell model for this study proved unsuccessful in obtaining relevant data. No significant levels of TNF $\alpha$ were secreted in response to any pathogen, including the positive control E. coli K12. After numerous attempts at detecting TNF $\alpha$ secretion from these cells in response to bacterial pathogens with the same lack of results, it was possible that 1) the A549 cell line simply did not inherently secrete $\mathrm{TNF} \alpha, 2$ ) the chemicals provided in the chosen ELISA kit were no longer viable from $>1$ year of storage, 3) the cells synthesized TNFa but did not effectively secrete it, or 4) our particular cell line was no longer able to secrete cytokines, possibly due to continued propagation and random mutation. Looking into the first possibility, I discovered that A549 cells have indeed been shown to secrete TNF $\alpha$ in previous research [25- 
28]. Therefore, this possibility is not the most likely reason for the observed phenomenon. Second, a standard curve with a strong correlation coefficient would prove the second assumption incorrect. Data from the twenty-four hour post-infection A549 cell line TNF $\alpha$ ELISA yielded an $\mathrm{R}^{2}$ value of 0.98937 , suggesting that the chemicals used were viable and the ELISA was performed correctly.

This leaves the third and fourth possibilities, in which TNF $\alpha$ was synthesized but was not secreted into the extracellular medium, or our cell line no longer makes cytokines due to extended propagations. Literature is not readily available on this subject, so further experimentation would be necessary for validation. These two possibilities could be distinguished by performing an experiment in which the organisms are allowed to invade our A549 cells, followed by quantitative real-time polymerase chain reaction (qRT-PCR) for detecting the abundance of TNF $\alpha$ transcript within the cell at designated time points. For the sake of time, this additional experiment was not yet performed; the focus was instead shifted to a new cell line.

The U937 human leukemic monocyte cell line was chosen as another appropriate model for an in vitro model for the human immune response to CF pathogens. The U937 cell line can exist in two different states: monocyte or macrophage. Monocytes are immature macrophages that circulate via the blood plasma until reaching a site of infection. At the site of infection monocytes are triggered to differentiate into macrophage by either directly binding to a PAMP or to pro-inflammatory cytokines released by other immune cells [29]. Within the CF lung, resident macrophages would monitor alveolar tissue while circulating monocytes in the blood would be recruited to the lung during infection and subsequently differentiated into macrophage in response to bacterial pathogens. However, both monocytes and macrophages can secrete 
cytokines. In order to observe the secretion of pro-inflammatory cytokine in both circumstances, U937 cells were chemically differentiated for some experiments but remained undifferentiated for others.

In the ELISA plates containing undifferentiated U937 cells, higher secretions of IL-8 in response to $B$. dolosa $\Delta f l i C$ were observed than for all other bacterial strains, even surpassing IL8 secretion in response to the positive control E. coli. Normally it would be counterintuitive to assume that a lack of flagella would result in an increased response by the immune system. However, I hypothesized that these $B$. dolosa polar flagella actually contribute to the bacteria's evasion of the human immune system. Although further research will be necessary to confirm the latter statement, this study provides evidence that the flagella of B. dolosa may contribute to the pathogen's evasion of the human immune system.

The B. dolosa fliC mutant that elicited the highest secretion of IL-8 in undifferentiated U937 cells was capable of expressing lateral flagella but not a polar flagellum; if multiple lateral flagella were expressed, it is possible that the less well-characterized lafA gene encodes the conserved amino acid residues for flagellar interaction with TLR5 that would trigger a larger immune response than would the WT expressing one or both flagella. In fact, when we look for the conserved residues in the predicted lateral flagellin protein sequence, I observe that Primary Interaction Domains A and B are present in the lateral flagellin protein. The lateral flagella have been found to assist in cell-cell and cell-surface adhesion during biofilm formation in other models of pathogenesis. These flagella may be expressed at lower levels in $B$. dolosa than the FliC polar flagellum in vivo so that detection via TLR5 is minimized, if the amino acid residue variation observed in the FliC interaction domain does in fact decrease the receptor's affinity for B. dolosa polar flagella. 
The lateral flagella's role in B. dolosa colonization can be partially explained when considering the results of the comparative swimming agar experiment for all three B. dolosa strains. In B. dolosa fliC mutant cells, colony diameters were restricted to an unchanging value of $0.6 \mathrm{~cm}$, a minimal amount of migration. If lateral flagella were expressed in the absence of fliC, these flagella may have triggered the strong adhesion of B. dolosa to the less viscous media of the swimming agar. If lateral flagella played no role in the small diameter of fliC mutant colony migration, there should be no observable difference in WT and lafA mutant migration diameters. However, lafA cells expressing polar flagella migrated to a larger diameter than WT cells in all five replicated plates. This finding may provide further evidence that lateral flagella do in fact play a role in localizing B. dolosa cells during initial colonization of host tissues.

In addition to these data, levels of IL-8 secretion from undifferentiated U937 cells were measured as a function of time (hours post-infection). When plotting IL-8 concentrations versus time for all tested bacterial species, I found that all B. dolosa strains elicited a greater increase in IL-8 secretion per hour than did the remaining species, the slopes of which were nearly horizontal (Figure 6). A possible explanation for this distinction is that the extracellular pathogens P. aeruginosa and E. coli led to more rapid U937 death than did the intracellular $B$. dolosa strains, which have been shown to persist in macrophage cells for several days in unpublished data by Dr. Yoder-Himes.

An inherent limitation to all in vitro models of mammalian systems is the lack of nutrient replenishment and waste removal by a functioning circulatory system, which could account for more rapid human cell death than would be expected in vivo. Furthermore, P. aeruginosa strains are capable of blocking the induction of the NF- $\mathrm{BB}$ pro-inflammatory pathway via a TLR5 antagonist [30]; induction of this pathway would normally lead to both monocyte differentiation 
to macrophage and secretion of multiple pro-inflammatory cytokines such as IL-8. This finding is the best explanation for the low levels of IL-8 secretion in undifferentiated U937 cells observed at both two and twenty-four hours post infection in response to both strains of $P$. aeruginosa. Differentiated cells were induced via the NF-kB pathway prior to bacterial invasion, so that $P$. aeruginosa inhibited neither differentiation nor cytokine secretion from these cells. This discussion can also account for the greater marginal increase in IL-8 secretion from undifferentiated to differentiated U937 cells in response to P. aeruginosa and E. coli strains as compared to IL-8 secretion from both cells types in response to strains of B. dolosa.

The continuation of this study will involve repeated invasion assays and ELISAs for proinflammatory cytokines, so that a more statistically reliable model can be formed. I also aim to measure cytokine fluctuation at more time points in replicate experiments, so that a more descriptive and accurate temporal model can be generated. Additionally, I will perform qRTPCR to measure levels of human transcripts relating to the immune response, such as those genes

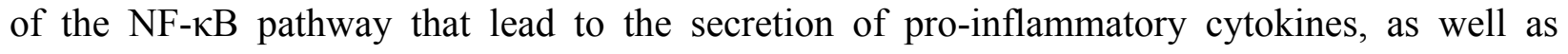
transcripts for those cytokines themselves. Further qRT-PCR for bacterial flagellar transcripts (fliC, lafA) will examine the expression of flagellar genes at varying times during infection and in solid versus liquid media. In addition, I can modify an existing published medium which resembles the mucous-filled epithelial lining of the CF lung [31] and I can test expression of all of these genes along with the solid and liquid media. This will provide genetic evidence in support of the proposed role of B. dolosa polar and lateral flagella described in this study. 


\section{Acknowledgements}

I would like to thank Dr. Deborah Yoder-Himes for her guidance on this project, as well as for cultivating a rich learning environment in which no questions go unanswered. I would also like to thank my additional lab members, Dave Jensen, Trusha Mehta, Danielle Gosney, Brad Clark, and Katherine King for their continued willingness to discuss issues and brainstorm better ways to perform experiments. Funding was provided by the University of Louisville Undergraduate Research Grant (URG).

\section{Literature Cited}

1. 2012 Annual Data Report, in Cystic Fibrosis Foundation Patient Registry 2013, Cystic Fibrosis Foundation.

2. Christopher H Goss, J.L.B., Exacerbations in cystic fibrosis 1: Epidemiology and pathogenesis. Thorax, 2007. 62: p. 360-367.

3. Jeffrey B. Lyczak, C.L.C., Geral B. Pier, Lung infections associated with cystic fibrosis. Clinical Microbiology Reviews, 2002. 15(2): p. 194-222.

4. Eshwar Mahenthiralingam, T.A.U., Joanna B. Goldberg, The multifarious, multireplicon Burkholderia cepacia complex. Nature Reviews: Microbiology, 2005. 3: p. 144-155.

5. Ludovic Vial, A.C., Marie-Christine Groleau and Eric Deziel, The various lifestyles of the Burkholderia cepacia complex species: a tribute to adaptation. Environmental Microbiology, 2011. 13(1): p. 1-12.

6. Adam Baldwin, E.M., Pavel Drevinek, Peter Vandamme, John R. Govan, David J. Waine, John J. LiPuma, Luigi Chiarini, Claudia Dalmastri, Deborah A. Henry, David P. Speert, David Honeybourne, Martin C. J. Maiden, Chris G. Downson, Environmental Burkholderia cepacia Complex Isolates from Human Infections. Emerging Infectious Diseases, 2007. 13(3).

7. Kimberley D. Seed, J.J.D., Development of Galleria mellonella as an Alternative Infection Model for the Burkholderia cepacia Complex. Infection and Immunology, 2008. 76(3): p. 1267-1275. 
8. Biddick, R., et al., Evidence of transmission of Burkholderia cepacia, Burkholderia multivorans and Burkholderia dolosa among persons with cystic fibrosis. FEMS Microbiology Letters, 2003. 228(1): p. 57-62.

9. Gautam Dantas, M.O.A.S., Rantimi D. Oluwasegun, George M. Church, Bacteria Subsisting on Antibiotics Science, 2008. 320(5872): p. 100-103.

10. Burkholderia dolosa Sequencing Project. 2010 [cited 2014 February 1]; Available from: (http://www.broadinstitute.org/).

11. Matthew T. G. Holden, H.M.B.S.-S., Lisa C. Crossman, Mohammed Sabaihia, Stephen D. Bentley, Ana M. Cerdeno-Tarraga, Nicholas R. Thomson, Nathalie Bason, Michael A. Quail, Sarah Sharp, Inna Cherevach, Carol Churcher, Ian Goodhead, Heidi Hauser, Nancy Holroyd, Karen Mungall, Paul Scott, Danielle Walker, Brian White, Helen Rose, Pernille Iversen, Dalila Mil-Homens, Eduardo P. C. Rocha, Arsenio M. Fialho, Adam Baldwin, Christopher Dowson, Bart G. Barrell, John R. Govan, Peter Vandamme, C. Anthony Hart, Eshwar Mahenthiralingam, Julian Parkhill, The Genome of Burkholderia cenocepacia J2315, an Epidemic Pathogen of Cystic Fibrosis Patients. Journal of Bacteriology, 2008. 191(1): p. 261-277.

12. Todar, K., Structure and Function of Bacterial Cells, in Todar's Online Textbook of Bacteriology2012.

13. Kirov, S.M., Bacteria that express lateral flagella enable dissection of the multifunctional roles of flagella in pathogenesis. FEMS Microbiology Letters, 2003. 224(2): p. 151-159.

14. CT French, I.T., TH Wu, T Teslaa, SM Beaty, W Wong, M Liu, I Schroder, MA Teitell, JF Miller, Dissection of the Burkholderia intracellular life cycle using a photothermal nanoblade. PNAS, 2011. 108(29): p. 12095-12100.

15. F Hayashi, K.S., A Ozinsky, TR Hawn, EC Yi, DR Goodlett, JK Eng, S Akira, DM Underhill, A Aderem, The innate immune response to bacterial flagellin is mediated by Toll-like receptor 5. Nature, 2001. 410(6832): p. 1099-1103.

16. Parihar, A.E., Timothy D.; Doseff, Andrea I. Monocytes and Macrophages Regulate Immunity through Dynamic Networks of Survival and Cell Death. 2010; Available from: http://www.ncbi.nlm.nih.gov/pmc/articles/PMC2956013.

17. G.S.K. Withanage, P.K., Paul Wigley, Claire Powers, Pietro Mastroenil, Heather Brooks, Paul Barrow, Adrian Smith, Duncan Maskell, Ian McConnell, Rapid Expression of Chemokines and Proinflammatory Cytokines in Newly Hatched Chickens Infected with Salmonella enterica Serovar Typhimurium. Infection and Immunology, 2004. 72(4): p. 2152-2159.

18. C. Ruef, D.M.J., S.E. Schlegel-Haueter, S. Suter, Regulation of cytokine secretion by cystic fibrosis airway epithelial cells. European Respiratory Journal, 1993. 6: p. 14291436. 
19. Horton RM, C.Z., Ho SN, Pease LR, Gene splicing by overlap extension: tailor-made genes using the polymerase chain reaction. Biotechniques, 1990. 8(5): p. 528-535.

20. Carolina M. Lopez, D.A.R., Lily A. Trunck, Herbert P. Schweizer, Versatile DualTechnology System for Markerless Allele Replacement in Burkholderia pseudomallei. Applied and Environmental Microbiology, 2009. 75(20): p. 6496-6503.

21. Dale A. Moulding, R.V.G., David G. Spiller, Michael R. H. White, David M. Tidd, Steven W. Edwards, Apoptosis is rapidly triggered by antisense depletion of MCL-1 in differentiating U937 cells. Blood, 2000. 96(5): p. 1756-1763.

22. Pablo Tamayo, D.S., Jill Mesirov, Qing Zhu, Sutisak Kitareewan, Ethan Dmitrovsky, Eric S. Lander, Todd R. Golub, Interpreting patterns of gene expression with selforganizing maps: Methods and application to hematopoietic differentiation PNAS, 1998. 96(6): p. 2907-2912.

23. Maria Ignez, C.G.E., Alain J Dessein, P. Xavier Elsas, Selection of U937 Histiocytic Lymphoma Cells Highly Responsive to Phorbol Ester-Induced Differentiation Using Monoclonal Antibody to the Eosinophil Cytotoxicity-Enhancing Factor. Blood, 1990. 75: p. 2427-2433.

24. C. Simon Shelley, J.M.T., Heiyoung Park, Omid C. Farokhzad, Erwin P. Bottinger, M. Amin Arnaout, During Differentiation of the Monocytic Cell Line U937, Pur(alpha) Mediates Induction of the CD11c beta-2 Integrin Gene Promotor. The Journal of Immunulogy, 2002. 168(8): p. 3887-3893.

25. Jun Yang, W.C.H., Donald J. Phillips, Deborah F. Talkington, Regulation of Proinflammatory Cytokines in Human Lung Epithelial Cells Infected with Mycoplasma pneumoniae. Infection and Immunology, 2002. 70(7): p. 3649-3655.

26. Yang, J., et al., Induction of proinflammatory cytokines in human lung epithelial cells during Chlamydia pneumoniae infection. Infect Immun, 2003. 71(2): p. 614-20.

27. Nold, M.F., et al., IL-37 is a fundamental inhibitor of innate immunity. Nat Immunol, 2010. 11(11): p. 1014-22.

28. Lee, J.H., et al., Intercellular adhesion molecule-1 mediates cellular cross-talk between parenchymal and immune cells after lipopolysaccharide neutralization. J Immunol, 2004. 172(1): p. 608-16.

29. Shogo Takashiba, T.E.V.D., Salomon Amar, Yoji Murayama, Aubrey W. Soskolne, Lior Shapira, Differentiation of Monocytes to Macrophages Primes Cells for Lipopolysaccharide Stimulation via Accumulation of Cytoplasmic Nuclear Factor kappaB. Infection and Immunology, 1999. 67(11): p. 5573-5578. 
30. Bart W. Bardoel, S.v.d.E., Michiel J. C. Pel, Jan Tommassen, Come M. J. Pieterse, Kok P. M. van Kessel, Jos A. G. van Strijp, Pseudomonas Evades Immune Recognition of Flagellin in Both Mammals and Plants. Plos: Pathogens, 2011. 7(8).

31. Palmer, K.L., et al., Cystic fibrosis sputum supports growth and cues key aspects of Pseudomonas aeruginosa physiology. J Bacteriol, 2005. 187(15): p. 5267-77.

32. Yoon, S.I., et al., Structural basis of TLR5-flagellin recognition and signaling. Science, 2012. 335(6070): p. 859-64. 


\section{APPENDIX}

\section{Supplemental Tables}

\section{Supplemental Figures}




\section{Supplemental Tables}




\begin{tabular}{|c|c|c|c|c|c|c|c|c|c|c|}
\hline & $\begin{array}{l}\text { P. aeruginosa } \\
\text { WT }\end{array}$ & $\begin{array}{l}\text { P. aeruginosa } \\
\Delta \text { fliC }\end{array}$ & \multicolumn{2}{|c|}{$\begin{array}{l}\text { B. dolosa } \\
\text { WT }\end{array}$} & \multicolumn{2}{|c|}{$\begin{array}{l}\text { B. dolosa } \\
\Delta \text { fliC }\end{array}$} & \multicolumn{2}{|c|}{$\begin{array}{l}\text { B. dolosa } \\
\text { AlafA }\end{array}$} & \multicolumn{2}{|c|}{$\begin{array}{l}\text { E. coli } \\
\text { K12 }\end{array}$} \\
\hline & 2 & 4 & 5 & 6 & 7 & 8 & 9 & 10 & 11 & 12 \\
\hline A & \multicolumn{6}{|c|}{ Standard Curve $(500$ or $250 \mathrm{pg} / \mathrm{mL}-1.95 \mathrm{pg} / \mathrm{mL})$} & \multicolumn{4}{|c|}{$\begin{array}{c}\text { Negative Controls (RPMI- } \\
1640 \text { Only) }\end{array}$} \\
\hline B & \multicolumn{10}{|c|}{$10^{8} \mathrm{CFU} / \mathrm{mL}$} \\
\hline $\mathrm{C}$ & \multicolumn{10}{|c|}{$10^{7} \mathrm{CFU} / \mathrm{mL}$} \\
\hline $\mathrm{D}$ & \multicolumn{10}{|c|}{$10^{6} \mathrm{CFU} / \mathrm{mL}$} \\
\hline $\mathrm{E}$ & \multicolumn{10}{|c|}{$10^{5} \mathrm{CFU} / \mathrm{mL}$} \\
\hline $\mathrm{F}$ & \multicolumn{10}{|c|}{$10^{4} \mathrm{CFU} / \mathrm{mL}$} \\
\hline $\mathrm{G}$ & \multicolumn{10}{|c|}{$10^{3} \mathrm{CFU} / \mathrm{mL}$} \\
\hline $\mathrm{H}$ & \multicolumn{10}{|c|}{$10^{2} \mathrm{CFU} / \mathrm{mL}$} \\
\hline
\end{tabular}

Supplemental Table 1: Invasion Assay and ELISA plate layout. CFU $/ \mathrm{mL}$ values correspond to the tenfold dilution series of each bacterial strain. The standard curve in row A was a two-fold dilution series of cytokine substrate representing detectable concentrations of cytokine for the ELISA kit used. $500 \mathrm{pg} / \mathrm{mL}$ was the top standard for TNF $\alpha ; 250 \mathrm{pg} / \mathrm{mL}$ was the top standard for IL-8. 


\begin{tabular}{|c|c|c|c|}
\hline Trial & B. dolosa WT & B. dolosa $\Delta$ fliC & B. dolosa $\Delta$ lafA \\
\hline 1 & 3.6 & 0.60 & 6.0 \\
\hline 2 & 3.8 & 0.60 & 4.6 \\
\hline 3 & 4.0 & 0.60 & 4.8 \\
\hline 4 & 4.0 & 0.60 & 5.2 \\
\hline 5 & 4.2 .0 & 0.60 & 5.8 \\
\hline Average & 3.92 & 0.60 & 5.28 \\
\hline Standard Deviation & 0.23 & 0 & 0.61 \\
\hline
\end{tabular}

Supplemental Table 2: Values of colony diameters in swimming agar for B. dolosa WT and isogenic mutants over five trials 


\begin{tabular}{|c|l|l|l|}
\hline Strain & $\begin{array}{l}\text { Undifferentiated [IL-8] } \\
(\mathbf{p g} / \mathbf{m L})\end{array}$ & $\begin{array}{l}\text { Differentiated [IL-8] } \\
(\mathbf{p g} / \mathbf{m L})\end{array}$ & \% Increase \\
\hline P. aeruginosa WT & 12.56439394 & 155.6933 & $1139.16 \%$ \\
\hline $\begin{array}{c}\text { P. aeruginosa } \\
\Delta \text { fliC }\end{array}$ & 4.227272727 & 238.5133 & $5542.25 \%$ \\
\hline B. dolosa WT & 114.57955 & 189.3283 & $65.24 \%$ \\
\hline B. dolosa $\Delta$ fliC & 274.99242 & 237.0583 & $-13.79 \%$ \\
\hline B. dolosa $\Delta$ lafA & 205.06818 & 203.7533 & $-0.64 \%$ \\
\hline E. coli K12 & 74.97727273 & 223.833 & $198.53 \%$ \\
\hline
\end{tabular}

Supplemental Table 3: Percent Increase in Optimal [IL-8] Secretion from Undifferentiated to Differentiated U937 cells. 


\section{Supplemental Figures}


A.
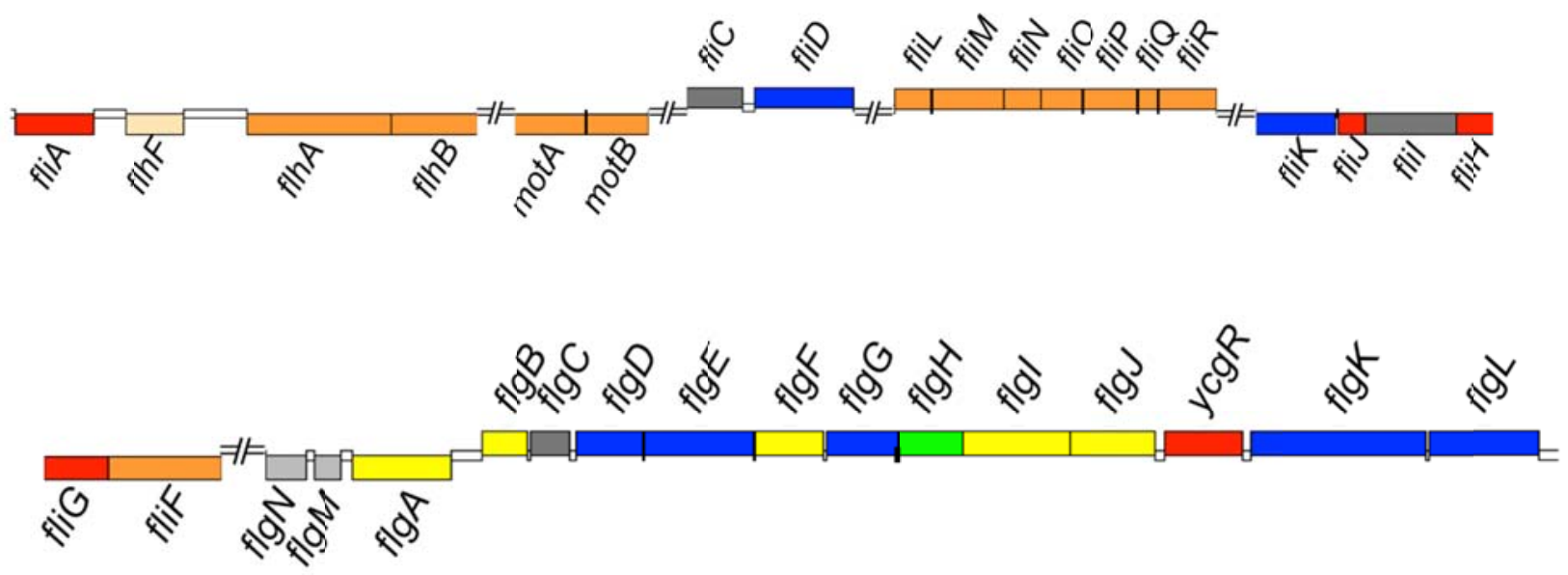

B.
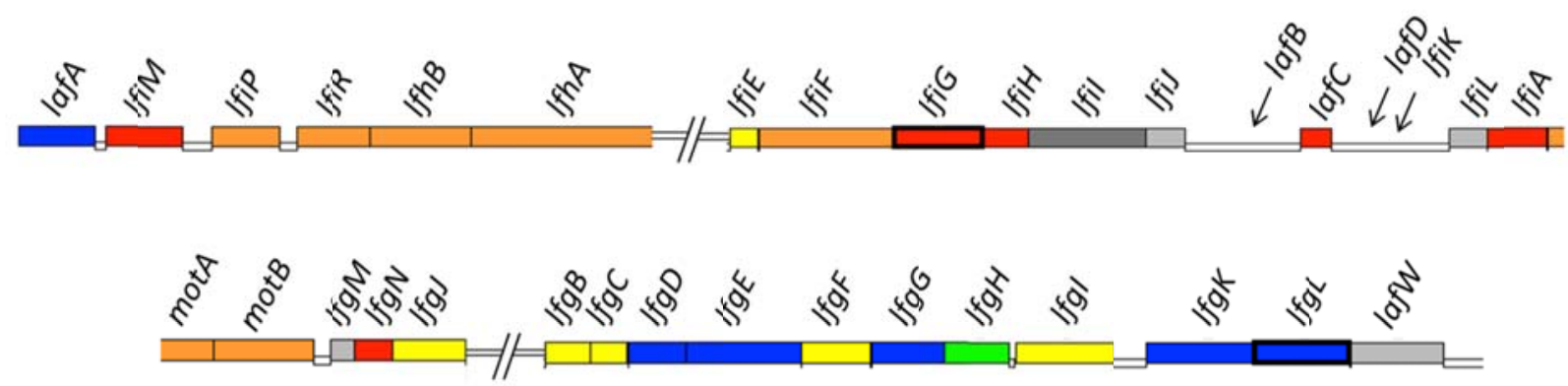

Supplemental Figure 1. Genetic loci encoding the chromosome 1-encoded polar flagella (A) or the chromosome 2-encoded lateral flagella (B) of B. dolosa. Genes are color coded according to their predicted subcellular localization: red - cytoplasmic; orange - cytoplasmic membrane; yellow periplasmic; green - outer membrane; blue - extracellular; light gray - unknown; dark gray - multiple localization sites; pink - no localization assigned. Three previously unannotated genes are noted in the lateral flagella loci. Homologous genes are noted by the names with "fl" indicating the polar flagella equivalent of the "lf" lateral flagella gene. Unpublished work by Dr. Yoder-Himes. 


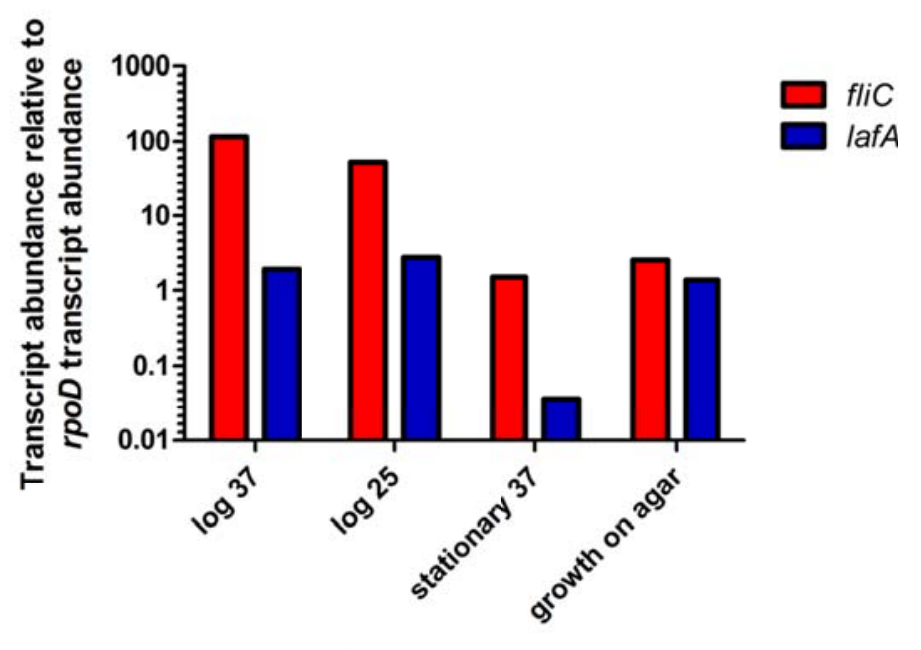

Growth condition

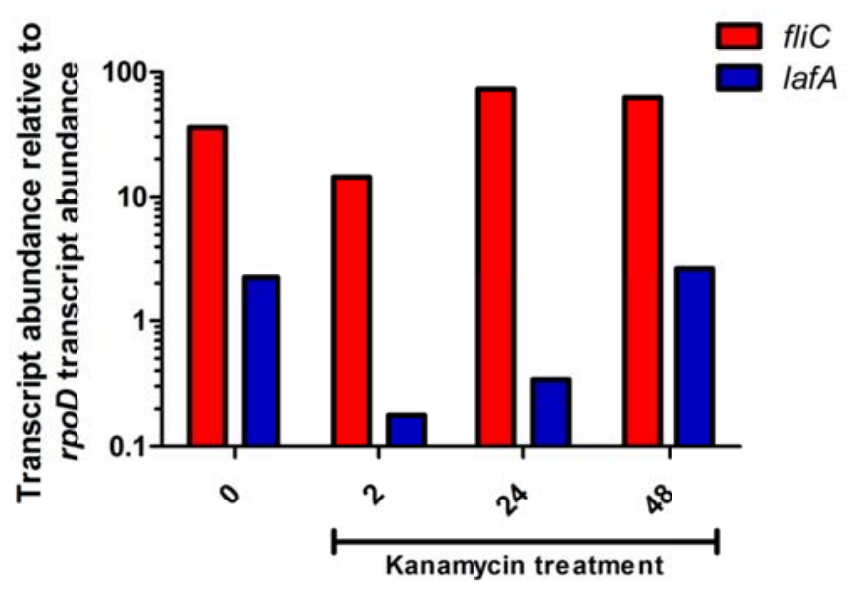

Hours post-infection

Supplemental Figure 2. Quantitative real-time PCR of B. dolosa fliC and lafA genes under varying conditions. Panel A show the relative transcript abundance of fliC and lafA under 4 growth conditions: logarithmic growth in liquid LB cultures at $37^{\circ} \mathrm{C}$, logarithmic growth in liquid LB cultures at $25^{\circ} \mathrm{C}$, overnight growth in liquid LB cultures at $37^{\circ} \mathrm{C}$, or after overnight growth on a LB agar plate at $37^{\circ} \mathrm{C}$. Quantitation is relative to $r p o D$, the gene encoding the major sigma factor, $\sigma^{70}$, to account for growth differences. Panel B shows the expression of these genes during invasion of A549 respiratory epithelial cells. Bacterial cells were washed, sampled (T0), allowed to invade for 2 hours, monolayers were washed and media with kanamycin was added, and samples were extracted immediately (T2), or 24, and 48 hours post-infection. Unpublished work by Dr. Yoder-Himes. 


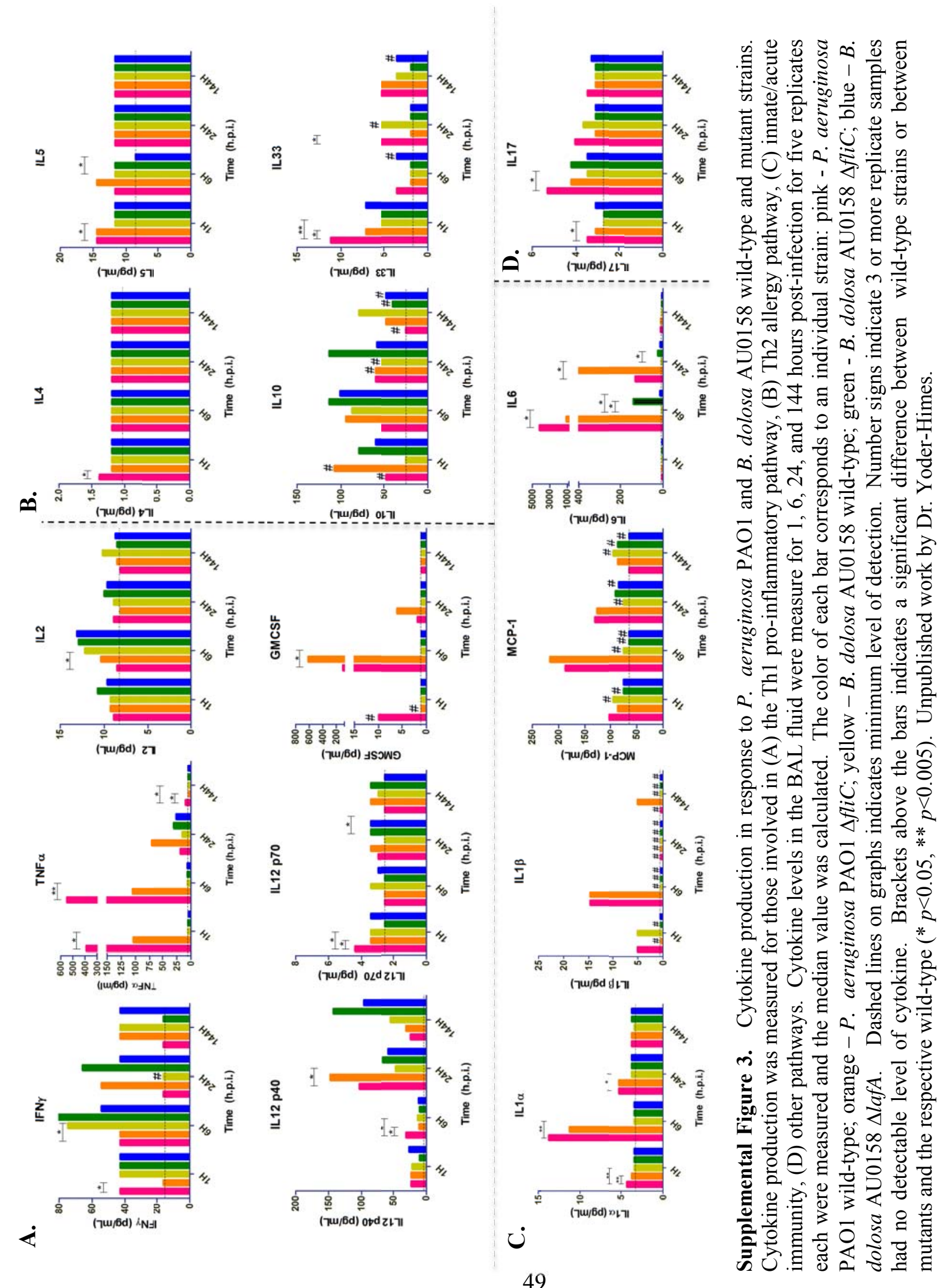


A.

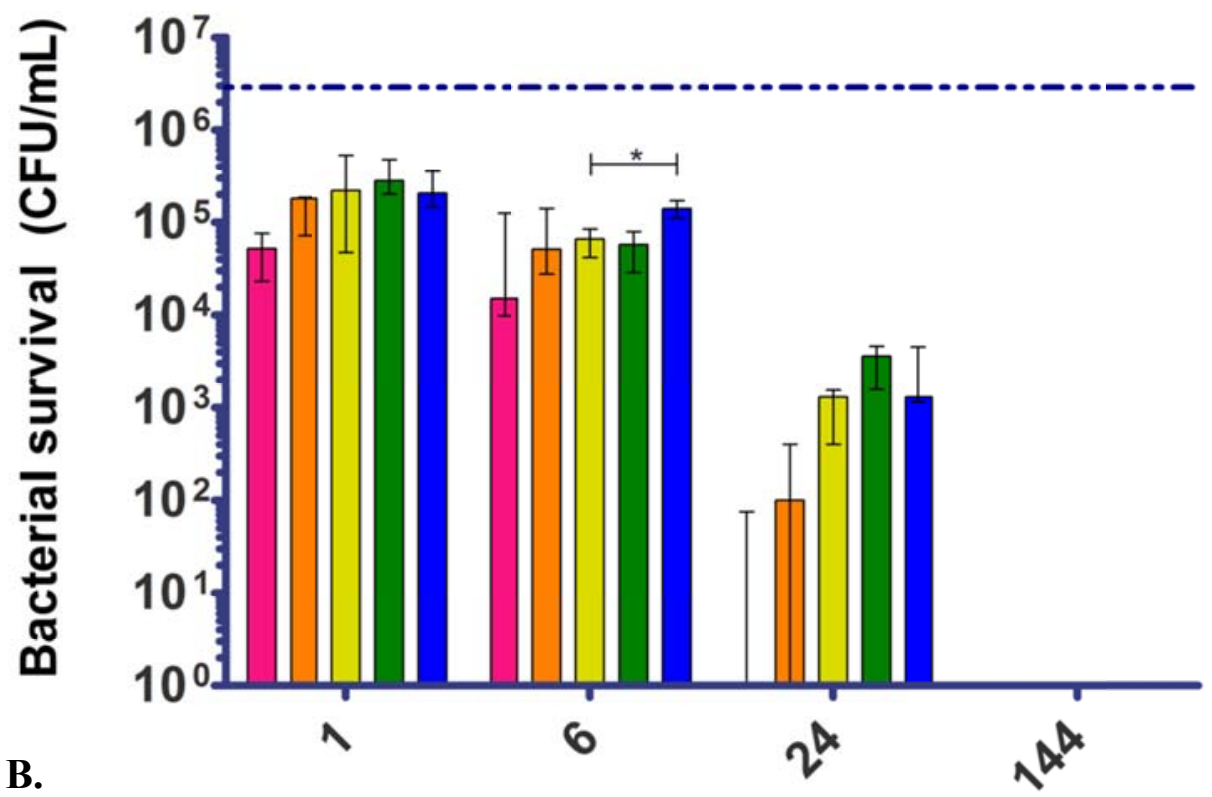

Time (h.p.i.)

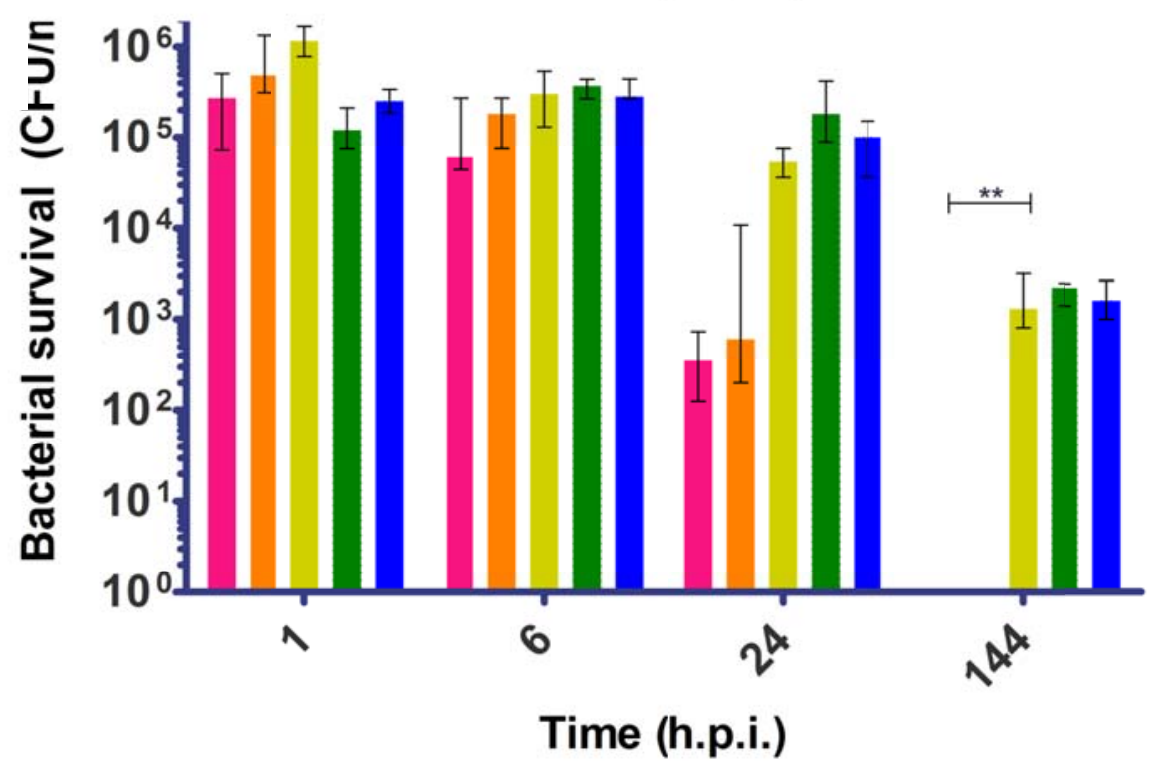

Supplemental Figure 4. Bacterial survival in the mouse lung over time. Bacteria levels in the (A) BAL fluid or (B) lung homogenates were measured by serial dilution and plating at 1, 6, 24, and 144 hours post-infection. The color of each bar corresponds to an individual strain: pink - P. aeruginosa PAO1 wild-type; orange - P. aeruginosa PAO1 $\Delta$ fliC; yellow - B. dolosa AU0158 wild-type; green - B. dolosa AU0158 $\Delta$ fliC; blue - B. dolosa AU0158 $\Delta$ lafA. The dashed line in each panel represents the initial inoculum. Error bars equal one standard deviation of the data. Brackets correspond to significant differences between strains $(* p<0.05, * * p<0.005)$ as calculated by 2 -way ANOVA. Unpublished work by Dr. Yoder-Himes. 


\section{Primary Interaction Domain A}

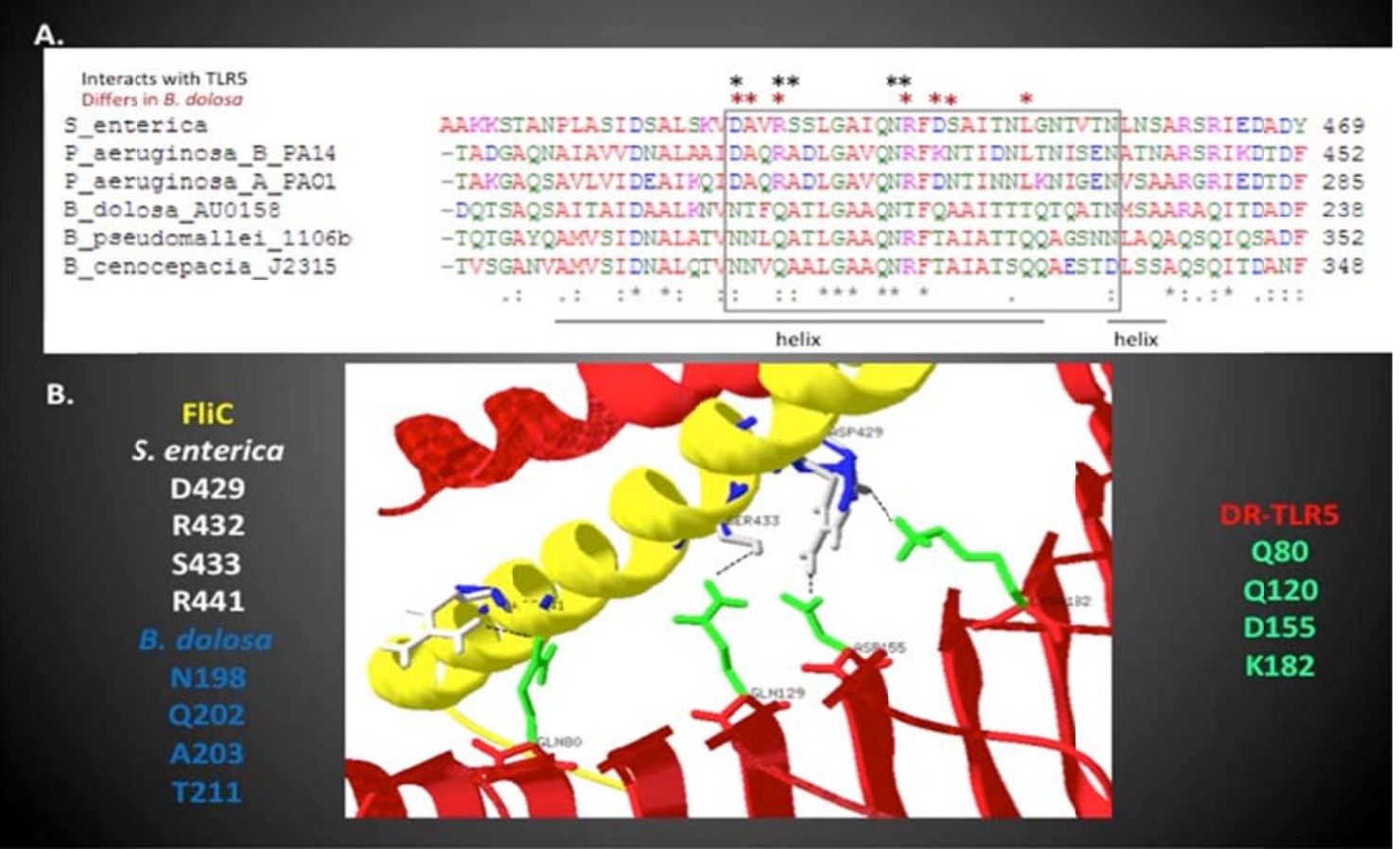

Supplemental Figure 5. Interactions between TLR and FliC in one interaction domain. (A) Comparison of parallel amino acid sequences corresponding to TLR5 Primary Interaction Domain A (Protein Database accession number \# 3V47 [32]) on the polar flagella of six bacterial pathogens. Black asterisks indicate residues directly involved in TLR5 interaction. Red asterisks indicate residues that differ in $B$. dolosa compared to $S$ enterica. Three specific residues involved in TLR5 interaction are varied for $B$. dolosa, resulting in conformational changes in B. dolosa polar flagella at this primary interaction domain. (B) The structural model of a portion of Primary Interaction Domain A is shown with the interacting amino acids are specifically represented. The red ribbons correspond to the zebrafish TLR5 molecule with the associated residues shown in green. The positions of the conserved residues in $S$. enterica are shown in white in the ribbon model along the yellow backbone of FliC; the variant $B$. dolosa residues are shown in blue. Unpublished work by Dr. Yoder-Himes. 


\section{Primary Interaction Domain B}
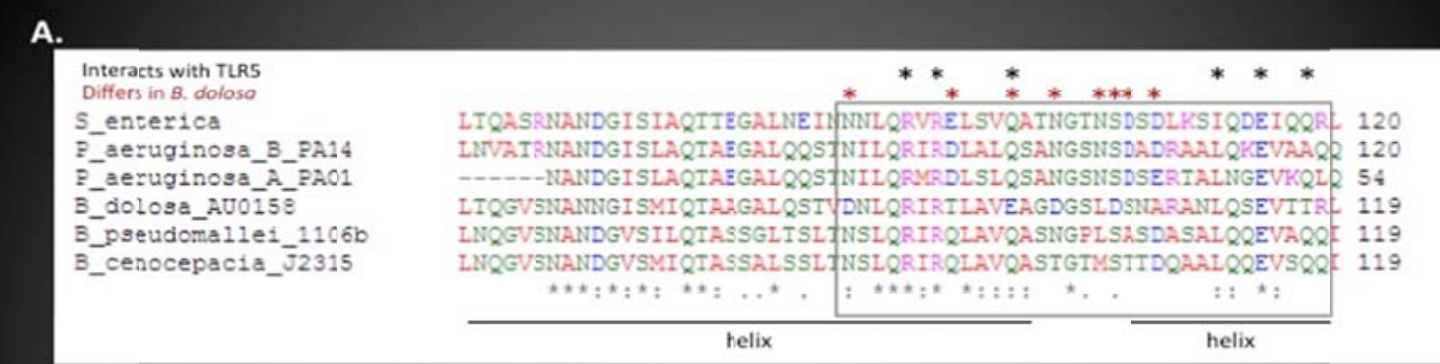

B.
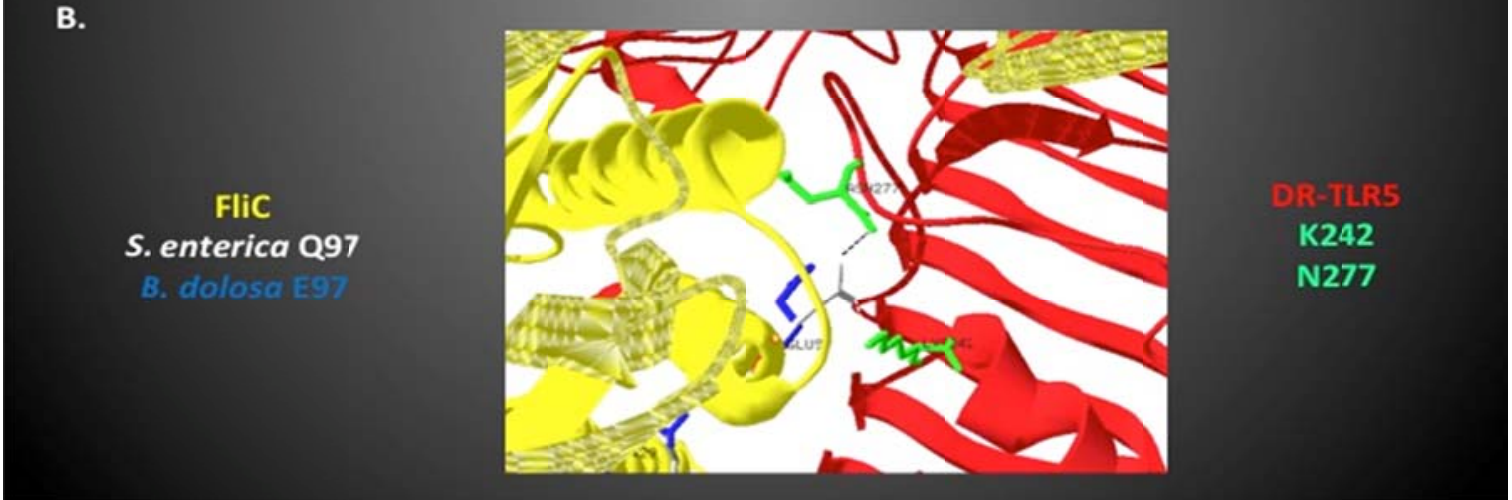

Supplemental Figure 6. Interactions between TLR and FliC in another interaction domain. (A) Comparison of parallel amino acid sequences corresponding to TLR5 Primary Interaction Domain B (Protein Database accession number \# 3V47 [32]) on the polar flagella of six bacterial pathogens. Although members of the Bcc vary at multiple residues, only those residues directly involved in TLR5 interaction are considered significant in affecting TLR5 binding. (B) The ribbon diagram of these domains are shown. Designations are described in the legend for Supplemental Figure 5. Unpublished work by Dr. Yoder-Himes. 


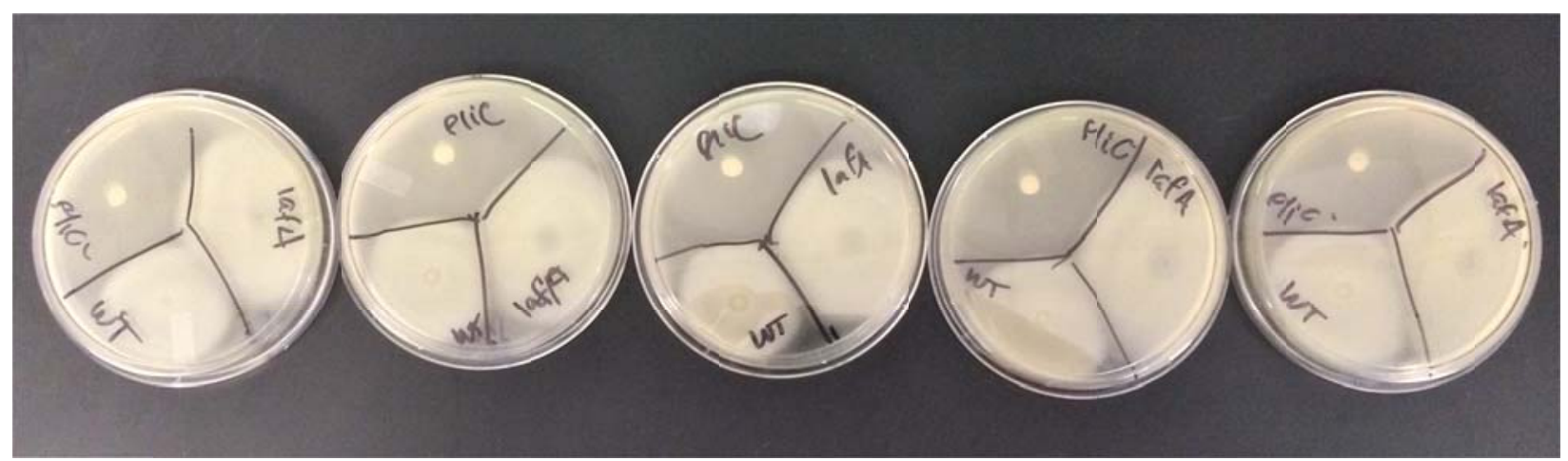

Supplemental Figure 7: Diameter of B. dolosa WT colony in swimming agar is compared to isogenic mutants in five trials. B. dolosa WT is in the bottom left corner of each plate; $B$. dolosa $\Delta$ fliC is in the upper portion; B. dolosa $\Delta$ lafA is in the upper/right portion. 


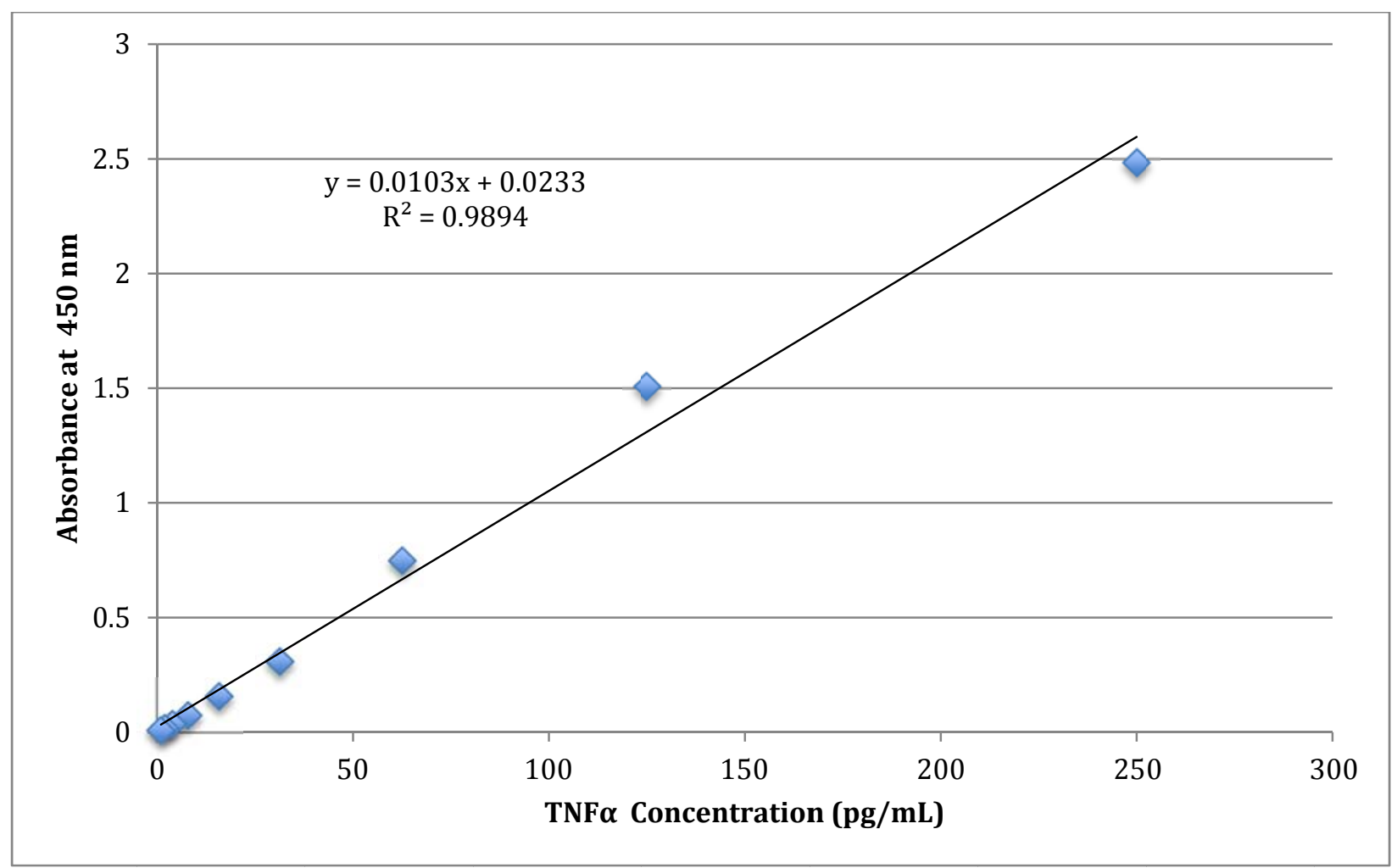

Supplemental Figure 8: Standard curve obtained during ELISA for TNF $\alpha$ production in A549 lung epithelial cells in response to bacterial pathogens at 24 hours post-infection. The range of TNF $\alpha$ concentrations listed reflects the measurable range of detectable TNF $\alpha$ concentrations for the ELISA kit used. Of note, the data point corresponding to [TNF $\alpha$ ] of $500 \mathrm{pg} / \mathrm{mL}$ was eliminated from the standard curve for this trial. The point was an outlier, but corresponded to a detectable level of TNF $\alpha$ so much higher than any level of TNF $\alpha$ actually detected in this particular experiment that its elimination had no bearing on the interpretation of the obtained data. 


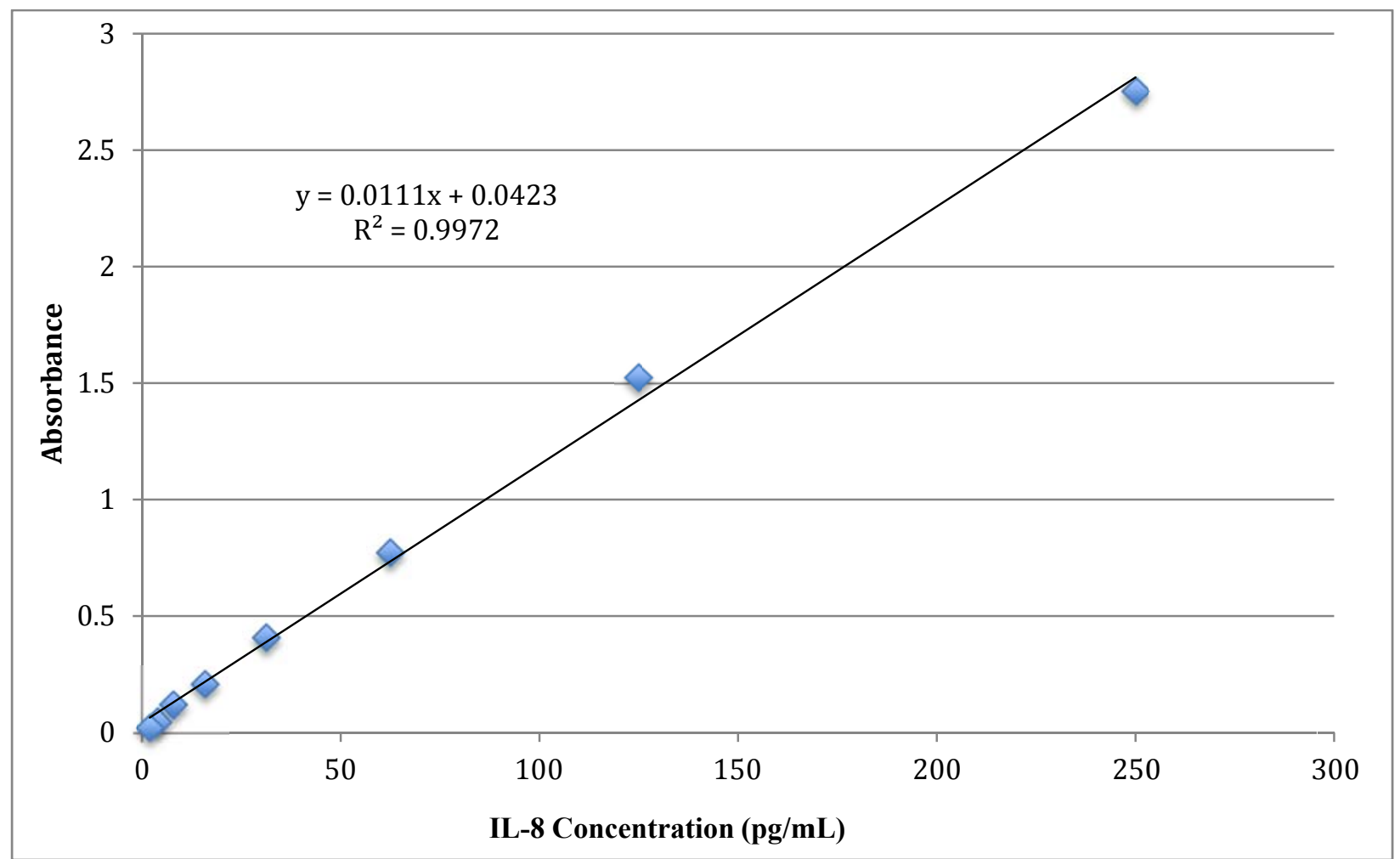

Supplemental Figure 9: Standard curve obtained during ELISA for IL-8 production in undifferentiated U937 macrophage-like cells in response to bacterial pathogens at 2 hours post-infection. Absorbance was calculated by subtracting absorbance at $570 \mathrm{~nm}$ from absorbance at $450 \mathrm{~nm}$. 


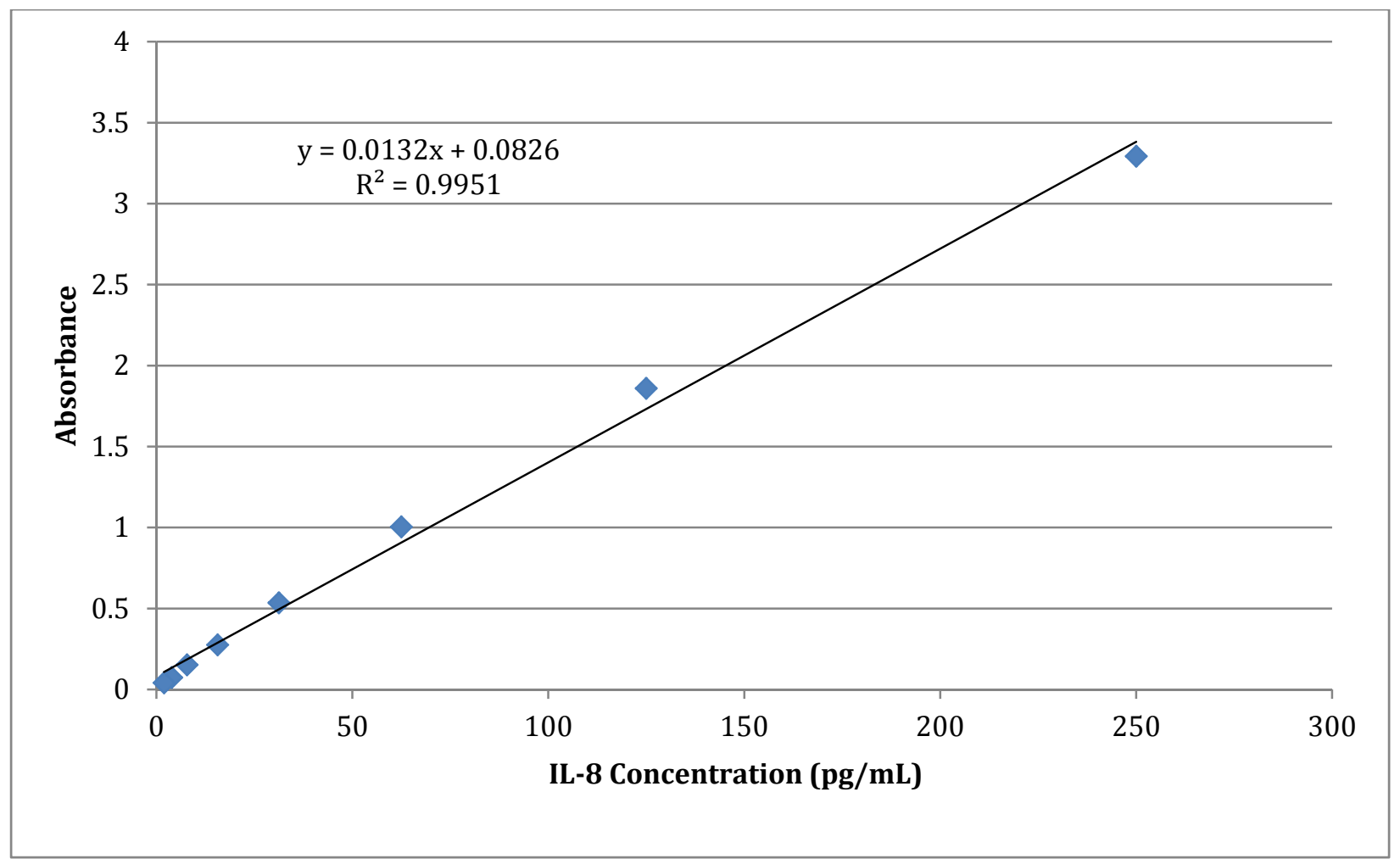

Supplemental Figure 10: Standard curve obtained during ELISA for IL-8 production in undifferentiated U937 cells at 24 hours post-infection. Absorbance was calculated by subtracting absorbance at $570 \mathrm{~nm}$ from absorbance at $450 \mathrm{~nm}$. 


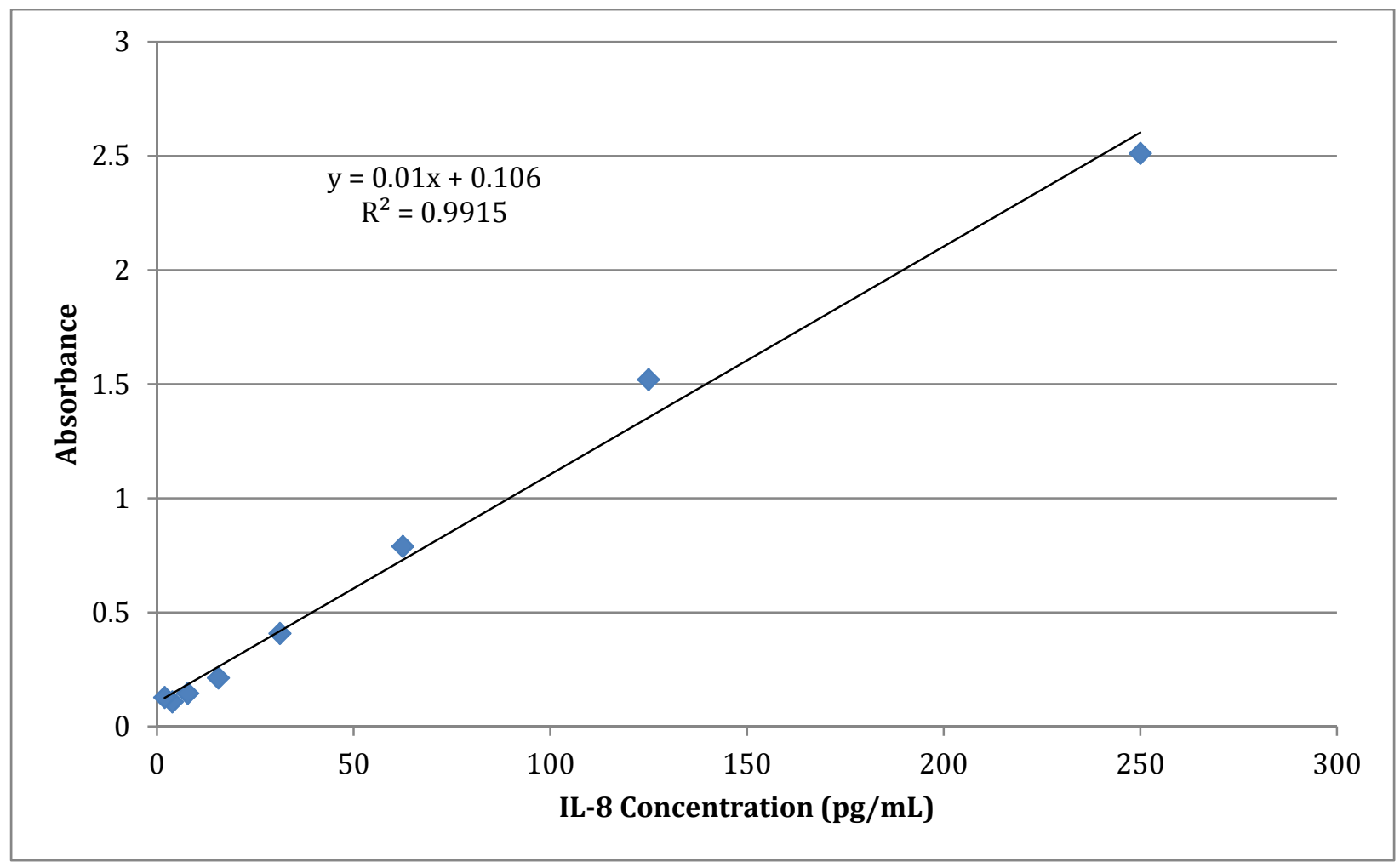

Supplemental Figure 11: Standard curve obtained during ELISA for IL-8 production in differentiated U937 cells at 24 hours post-infection. Absorbance was calculated by subtracting absorbance at $570 \mathrm{~nm}$ from absorbance at $450 \mathrm{~nm}$. 